\title{
EIBEA 2019
}

Encontro Iberoamericano de Estudos do Antropoceno Encuentro Iberoamericano de Estudios del Antropoceno

Programa \& Resumos

Programa \& Resúmenes

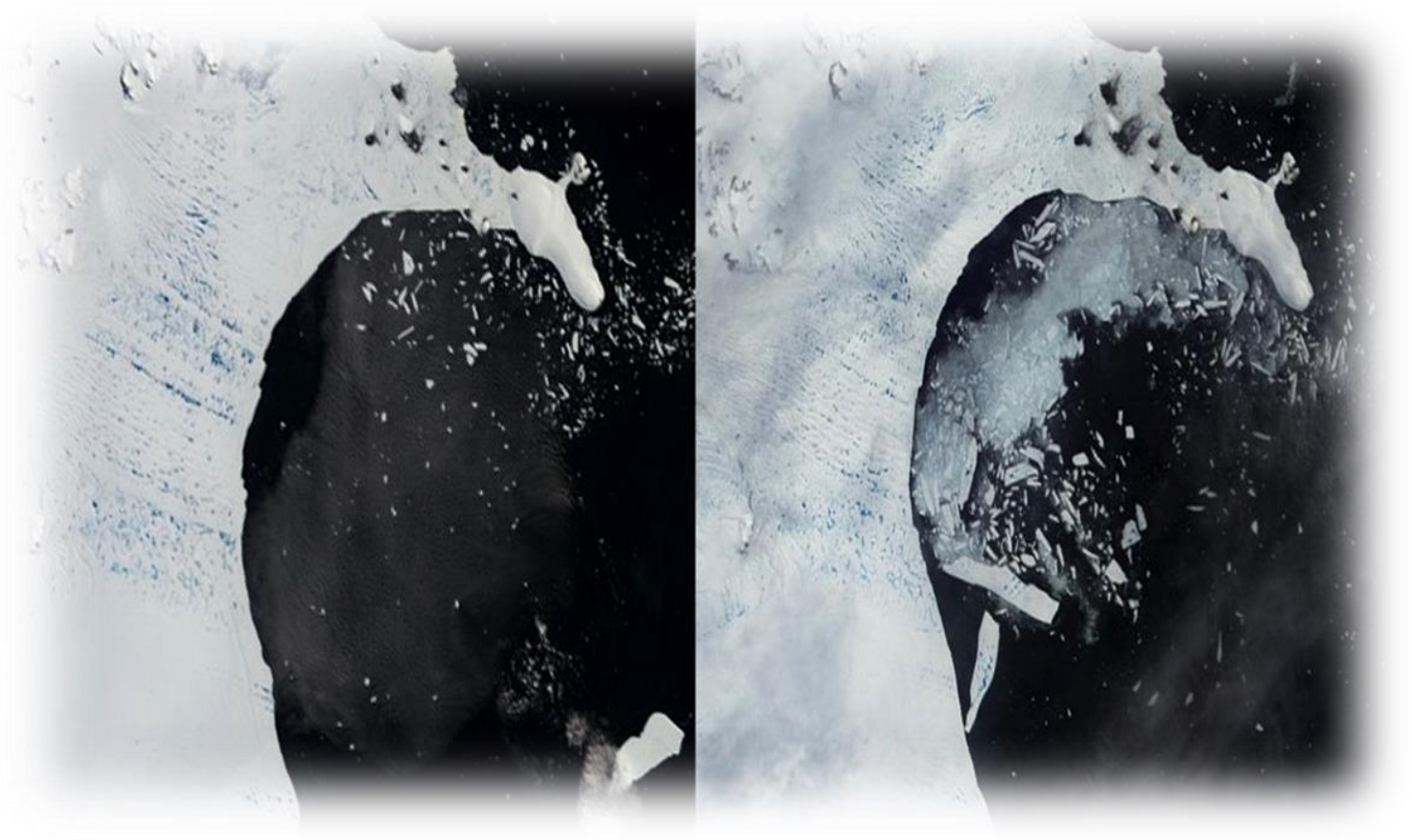





\section{FICHA TÉCNICA}

\section{Título}

EIBEA 2019. Encontro Iberoamericano de Estudos do Antropoceno. Livro de resumos

\section{Editores}

João Ribeiro Mendes \& Bernhard Josef Sylla

\section{Comissão científica/Comité científico}

Álvaro Manuel Rodrigues Balsas (U. Católica Portuguesa), Bruno Paulo Castendo Rego (U. de Lisboa). Cláudia Maria Novais Toriz da Silva Ramos (U. Fernando Pessoa), Darrel Moellendorf (Goethe-Universität Frankfurt), Marcelino Agís Villaverde (U. de Santiago de Compostela), Marco Marian (U. de Santiago de Compostela), Maria do Carmo Pinheiro e Silva Cardoso Mendes (U. do Minho), Maria Isabel do Amaral Antunes Vaz Ponce de Leão (U. Fernando Pessoa), Renato Filipe Faria Henriques (U. do Minho), Richard Stahel (U. Konstant'na Filozofa v Nitre), Rui Pedro Andrade Paes Colares Mendes (U. do Porto), Sérgio Lira (Green Lines Institute for Sustainable Development)

\section{Edição/Edición}

INfAST. Institute for Anthropocene Studies

1. ${ }^{\mathrm{a}}$ edição - 2019

\section{DOI}

10.21814/1822.62975

ISBN

978-989-33-0397-9

\section{Apoios/Apoyos}




\section{Índice}

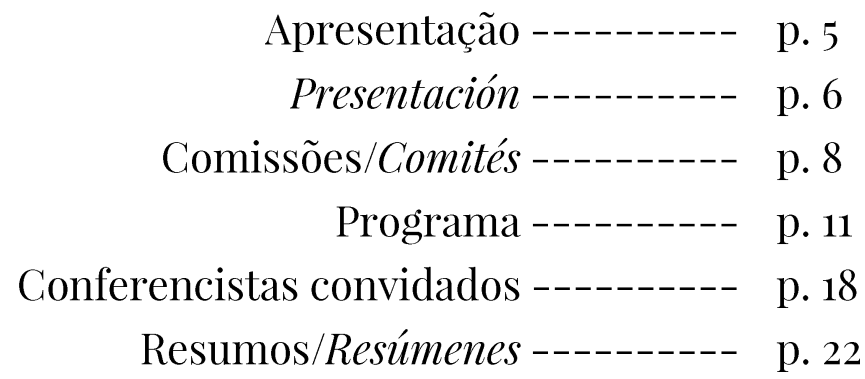




\section{Apresentação}

O EIBEA-Encontro Iberoamericano de Estudos do Antropoceno realizase durante os dias 11, 12 e 13 de junho de 2019 na Universidade do Minho (Braga, Portugal). O EIBEA pretende constituir uma ocasião para estudiosos provenientes das Ciências da Terra, das Ciências Sociais e das Humanidades cruzarem as suas distintas abordagens e construírem um fecundo diálogo interdisciplinar sobre a problemática do Antropoceno. O EIBEA projeta vir a ser uma "zona de intercâmbio" regular para os Estudos do Antropoceno.

O conceito de "Antropoceno" foi proposto, em 200o, pelo Nobel da química holandês (pelos seus trabalhos sobre a camada de ozono) Paul Crutzen e pelo limnologista estadunidense Eugene Stoermer para designar a entrada num novo capítulo da história da Terra caraterizado pela espécie humana ter adquirido um poder geomórfico, sem precedentes, equivalente ao de uma força natural. Esse facto da nossa espécie estar a provocar aquecimento global, outras alterações climáticas e ameaçar a sustentabilidade do bioma terrestre e, por consequência, a sobrevivência, no futuro próximo, da civilização e do ser humano, coloca a problemática do Antropoceno no topo dos assuntos que urge pensar e discutir.

URL: http://www2.ceps.ilch.uminho.pt/eibea2019 


\section{Presentación}

El EIBEA-Encuentro Iberoamericano de Estudios del Antropoceno se celebra durante los días 11, 12 y 13 de junio de 2019 en la Universidade do Minho (Braga, Portugal). El EIBEA será una ocasión que permitirá a estudiosos provenientes de las Ciencias de la Tierra, de las Ciencias Sociales y de las Humanidades la presentación de sus distintos enfoques y la construcción de un fecundo y disciplinariamente entrecruzado diálogo sobre la problemática del Antropoceno. El EIBEA proyecta también convertirse en una "zona de intercambio" regular para los Estudios del Antropoceno.

El concepto de "Antropoceno" fue propuesto en 2000 por el Nobel de la química holandés (por sus trabajos sobre la capa de ozono) Paul Crutzen y por el limnólogo norteamericano Eugene Stoermer para designar la entrada en un nuevo capítulo de la historia de la Tierra caracterizado por la especie humana haber adquirido un poder geomórfico, sin precedentes, equivalente al de una fuerza natural. Este hecho de que nuestra especie está provocando un calentamiento global, otros cambios climáticos y amenazando la sostenibilidad del bioma terrestre y, por consiguiente, la supervivencia en el futuro próximo de la civilización y del ser humano, plantea la problemática del Antropoceno cómo prioridad que es urgente pensar y discutir.

URL: http://www2.ceps.ilch.uminho.pt/eibea2019 



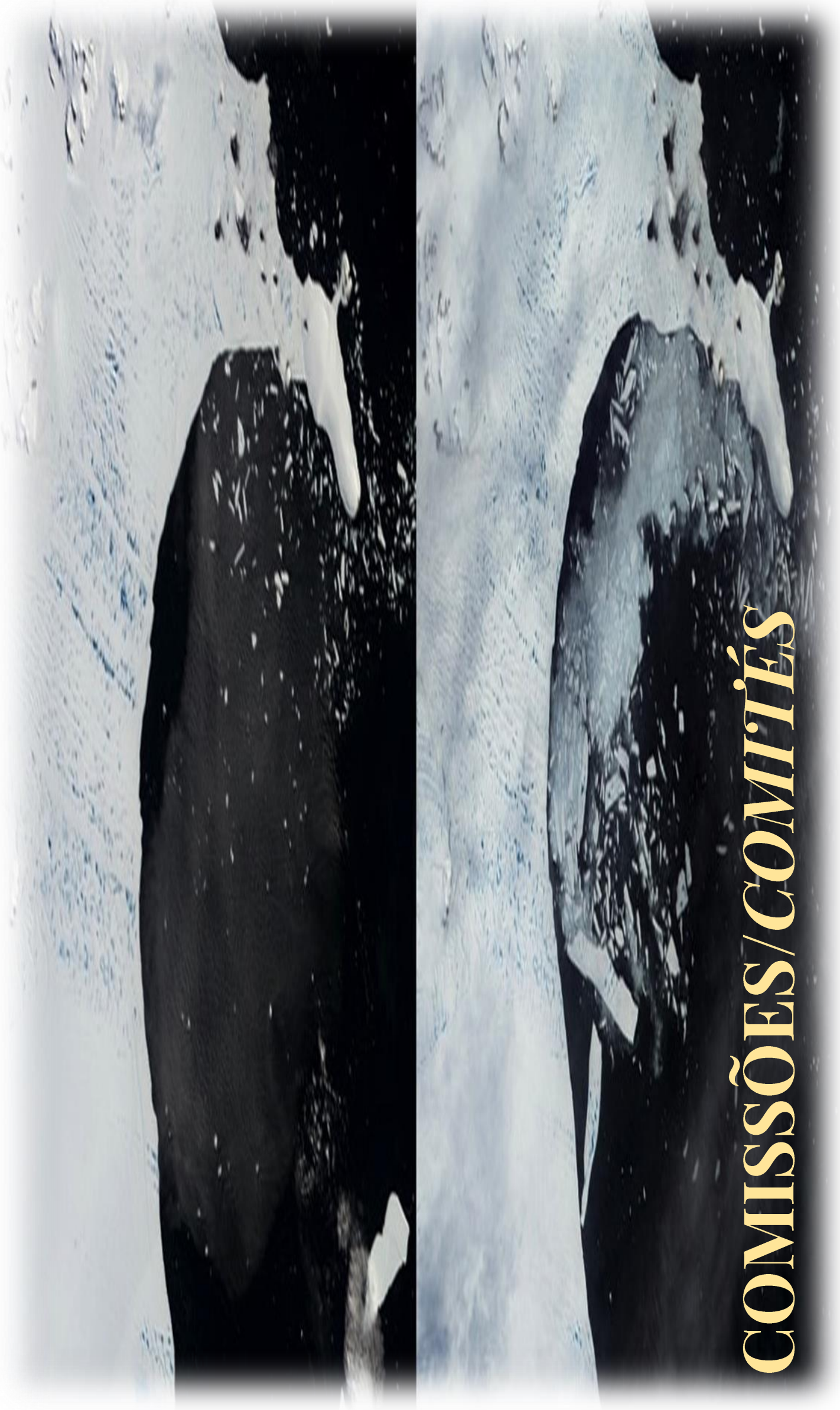




\section{Comissões/Comités}

\section{Comissão organizadora/Comité organizador}

João Ribeiro Mendes (U. do Minho)

Bernhard Josef Sylla (U. do Minho)

\section{Secretariado/Secretaria}

Ana Maria Pereira

Paulo Martins

\section{Comissão científica/Comité científico}

Álvaro Manuel Rodrigues Balsas (U. Católica Portuguesa)

Bruno Paulo Castendo Rego (U. de Lisboa)

Cláudia Maria Novais Toriz da Silva Ramos (U. Fernando Pessoa)

Darrel Moellendorf (Goethe-Universität Frankfurt)

Marcelino Agís Villaverde (U. de Santiago de Compostela)

Marco Marian (U. de Santiago de Compostela)

Maria do Carmo Pinheiro e Silva Cardoso Mendes (U. do Minho)

Maria Isabel do Amaral Antunes Vaz Ponce de Leão (U. Fernando Pessoa)

Renato Filipe Faria Henriques (U. do Minho)

Richard Stahel (U. Konstant'na Filozofa v Nitre)

Rui Paes Mendes (U. do Porto)

Sérgio Lira (Green Lines Institute for Sustainable Development)

e todos os membros da Comissão Organizadora 



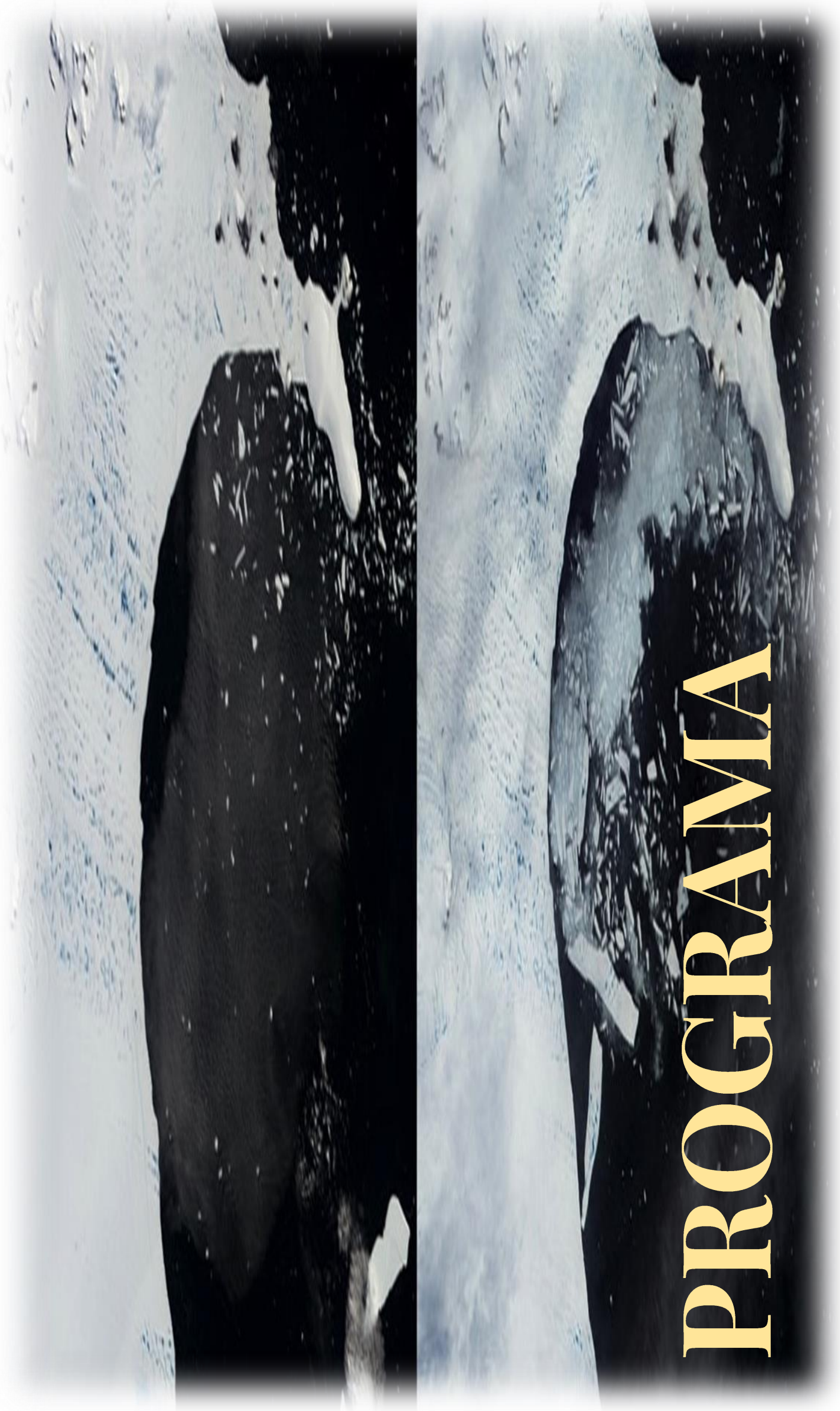




\section{Programa}

\section{EIBEA 2019}

Encontro Iberoamericano de Estudos do Antropoceno

Encuentro Iberoamericano de Estudios del Antropoceno

11-13/6/2019 | Universidade do Minho

Programa/Programa

\section{Junho/Junio}

oghoo | Receção/Recepción (ILCH, Edifício 05, piso o)

ogh3o | Sessão de abertura/Sesión de apertura (Auditório ILCH)

Pró-Reitor da Universidade do Minho: José Filipe Vaz

Presidente do Instituto de Letras e Ciências Humanas: João Cardoso Rosas

Presidente da Câmara Municipal de Baião: Paulo Pereira

Organizadores: João Ribeiro Mendes e Bernhard Josef Sylla

1ohoo | Conferência plenária/Conferencia plenaria 1 (Auditório ILCH): Manuel Arias Maldonado (U. Málaga), Significados del Antropoceno: una exploración conceptual de la nueva época geológica

Moderador:João Ribeiro Mendes

11hoo | Pausa para café/Pausa para el café 
$\mathbf{1 1 h} 3 \mathbf{0}$ | Sessões/Sesiones

\# I (Auditório ILCH)

Moderador(a): Sérgio Lira

Isabel Ponce de Leão (U. Fernando Pessoa) \& Wlodzimierz Szymaniak (U. Jean Piaget, Cabo Verde), Angola/Luanda: a consciência do Antropoceno em Mais um dia de vida de Ryszard Kapuscinski

Maria do Carmo Mendes (U. Minho), O Pós-Antropoceno em Oryx and Crake de Margaret Atwood

Cláudia Castro de Andrade (U. Estado do Rio de Janeiro), Aspetos filosóficos do Antropoceno: o lugar da transmissão cultural em nossas representações simbólicas

* II (Sala CEPS)

Moderador(a): Rui Paes Mendes

Cynthia Luderer (U. Minho), Entre memórias e ideologias: um nebuloso cenário para as escolhas alimentares

Rosa María Ricoy (U. Vigo) \& Hermes de Andrade Júnior (U. Católica Portuguesa, Braga), (In) Segurança alimentar e nutricional no Antropoceno: Um estudo comparado entre Brasil e Espanha

Flávio de Oliveira (U. Federal do Pará), O Antropoceno e a revolução dos biomateriais. Diálogos entre Filosofia e Ciência dos Materiais na Amazónia do século XXI

13hoo | Almoço/Comida 
15hoo | Sessões/Sesiones

\# III (Auditório ILCH)

Moderador(a): Bruno Rego

Maria Adelaide Pacheco (U. Évora), A saída do Antropoceno e a proposta de desautomatização de Bernard Stiegler

Jane Guimarães (U. Évora), A Mecanosfera de Deleuze e Guattari

Bernhard Sylla (U. Minho), O Antropoceno - um naufrágio com espectador?

$\mathbf{1 6 h 3 0}$ | Sessões/Sesiones

* IV (Auditório ILCH)

Moderador(a): Bernhard Josef Sylla

Richard Stahel (U. Konstant'na Filozofa v Nitre), Sustainable retreat concept as an answer to anthropocene challenges

Thomas Heyd (U. Victoria, Canada), El antropoceno y el contrato natural

Hermes de Andrade Júnior (U. Católica Portuguesa, Braga), Logística Reversa: alguns aspectos sobre a aplicabilidade da política de resíduos sólidos no Brasil

João Ribeiro Mendes (U. Minho), O Antropoceno como objeto-fronteira

18h3o | Fim do $1^{\circ}$ dia/Fin del primer día

2ohoo | Jantar do Encontro/Cena del Encuentro 


\section{Junho/Junio}

1ohoo | Sessões/Sesiones

\# V (Auditório ILCH)

Moderador(a): Acílio Estanqueiro Rocha

Marcelino Agís Villaverde (U. Santiago de Compostela), La felicidad sostenible: nuevos modos de pensar lo humano en el antropoceno

Rocio Carolo Tosar (U. Santiago de Compostela), El ser humano saudoso: la importancia del sentimiento en la reflexión filosófica

Flávio Freitas (U. Federal do Maranhão), A relação entre homem e natureza no capítulo 1 de $O$ Anti-Édipo

\# VI (Sala CEPS)

Moderador(a): Hermes de Andrade Júnior

Rui Paes Mendes (U. Porto), As pestes em tempo do primado da ciência

Marcelo Moraes (U. Estado do Rio de Janeiro) \& Mariane Bitteti (U. Estado do Rio de Janeiro), Ontologia Ubuntu: Natureza ser-com Homem

Alexandre Nascimento (U. Estado de Minas Gerais), Juliana Magno (U. Estado de Minas Gerais), Anderson de Oliveira (U. Estado de Minas Gerais), Karine Oliveira (U. Estado de Minas Gerais), Farley Lobo (U. Estado de Minas Gerais) \& Henrique Nascimento (Prefeitura Municipal de Belo Horizonte), Observatório de Políticas Públicas pela Sustentabilidade (OPPS): Aproximando ciência, gestores políticos e cidadãos pela sustentabilidade no Brasil 
$\mathbf{1 1 h} 3 \mathbf{0}$ | Sessões/Sesiones

\# VII (Auditório ILCH)

Moderador(a): João Ribeiro Mendes

Cláudia Toriz Ramos (U. Fernando Pessoa), Desenvolvimento sustentável e democratização, no Antropoceno: o caso da Guiné-Bissau

Ana Raquel Matos (U. Coimbra), António Carvalho (U. Coimbra) \& Vera Ferreira U. Coimbra), Antropoceno e alterações climáticas no Parlamento: atores, imaginários e pós-política no discurso político portuguêes (1990- 2018)

Anabela Carvalho (U. Minho), Envolvimento político com as questões ambientais e a agenda das ciências sociais e humanas

13hoo | Almoço/Comida

15hoo | Sessões/Sesiones

* VIII (Auditório ILCH)

Moderador(a): Maria do Carmo Mendes

Sérgio Lira (Green Lines Institute for Sustainable Development), Museus e periodização: já estamos no Antropoceno?

Bruno Rego (U. Lisboa), Paris no Século XX, Lisboa no Século XXI ou a Monotonização do Mundo: A Ideia de Cidade no Antropoceno

António Carvalho (U. Coimbra), Ana Raquel Matos (U. Coimbra) \& Vera Ferreira (U. Coimbra), As políticas ontológicas do Antropoceno

16h3o | Conferência plenária/Conferencia plenaria 2 (Auditório ILCH): Orfeu Bertolami (U. Porto) e Frederico Francisco (U. Porto), Um modelo Físico para o Antropoceno: o Sistema Terrestre enquanto sistema dinâmico e as Alterações Climáticas

Moderação: Bernhard Sylla

17h3o Fim do $2^{\circ}$ dia/Fin del segundo día 


\section{Junho/Junio}

oghoo | Universidade do Minho: partida de autocarro para Baião/salida en autobús hacia Baião

11hoo | Chegada a Baião/Llegada a Baião

11 h15 | Receção na Câmara Municipal/Recepción en el Ayuntamiento

11 45 | Visita à Área Protegida Regional da Serra da Aboboreira (futuro Geoparque)/ Visita al Área Protegida Regional de la Sierra de Aboboreira (futuro Geoparque)

12h3o | Almoço/Comida

$\mathbf{1 4 h o o}$ | Atividades na zona ribeirinha do Douro/Actividades en la zona ribereña del Duero

$\mathbf{1 6 h o o}$ | Visita ao Mosteiro de Ancede/Visita al Monasterio de Ancede

17hoo | Regresso de autocarro à Universidade do Minho/Regreso de autobus a la Universidade do Minho

18h30 | Chegada à Universidade do Minho/Llegada à Universidade do Minho 



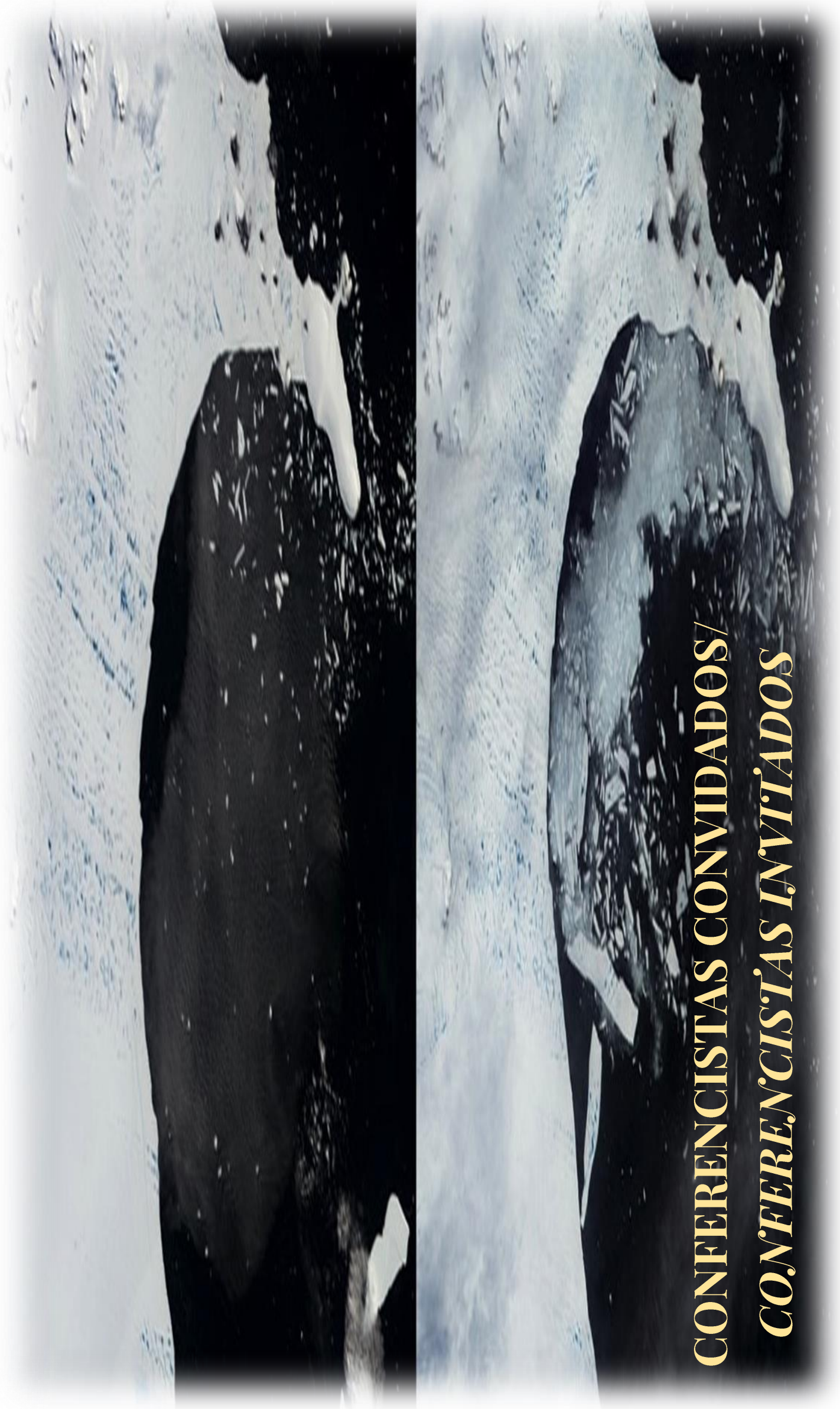




\section{Conferencistas convidados/ Conferencistas invitados}

Conferência plenária 1/Conferencia plenaria 1: Significados del Antropoceno: una exploración conceptual de la nueva época geológica

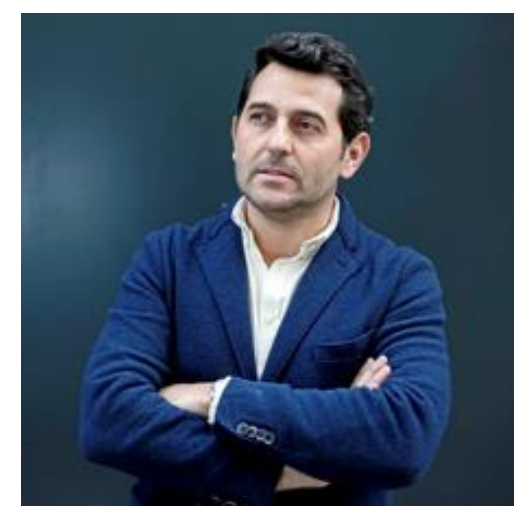

Manuel Arias Maldonado (1974) es Profesor Titular de Ciencia Política en la Universidad de Málaga, donde se licenció en Derecho y defendió una tesis en Ciencia Política galardonada con el Premio Extraordinario de Doctorado. Ha sido becario Fulbright en la Universidad de Berkeley (2004-2005), Salvador de Madariaga en el Rachel Carson Center de la Universidad de Munich (2011) y en el Department of Environmental Studies \& Animal Studies en la New York University (2017), así como investigador visitante en las de Munich, Keele, Oxford y Siena. Su investigación académica ha girado, principalmente, en torno a la dimensión política y filosófica del medio ambiente, la teoría de la democracia, el liberalismo político, las nuevas tecnologías, el populismo y la afectividad política. Es autor de las monografías Sueño y mentira del ecologismo. Naturaleza, sociedad, democracia (Siglo XXI, 2008), Real Green. Sustainability after the End of Nature (Ashgate, 2012; Premio al Mejor Libro del Año 2012 otorgado por la Asociación Española de Ciencia Política), Environment \& Society. Socionatural Relations in the Anthropocene (Springer, 2015) La democracia sentimental. Política y emociones en el siglo XXI (Página Indómita, 2016) y Antropoceno. La politica en la era humana (Taurus, 2018). En enero de 2019 apareció $\mathrm{Fe}$ )Male Gaze, ensayo sobre las relaciones entre hombre y mujer en la era del \#metoo, en los Nuevos Cuadernos de Anagrama. Ha publicado artículos en numerosas revistas académicas nacionales e internacionales. Su atención a la teoría política es compatible con la crítica cultural y el ensayismo. Es colaborador habitual de Revista de Libros (donde conduce además un blog Torre de marfil), Letras Libres (a cuyo consejo editorial pertenece), Revista de Occidente, Cuadernos Hispanoamericanos o Lettre International Deutschland, entre otras. Es miembro del Consejo de Redacción de la Revista Española de Ciencia Política y del Consejo Asesor de la colección Estudios Políticos del CEPC. 
Conferência plenária 2/Conferencia plenaria 2: Um modelo Físico para o Antropoceno: o Sistema Terrestre enquanto sistema dinâmico e as Alterações Climáticas

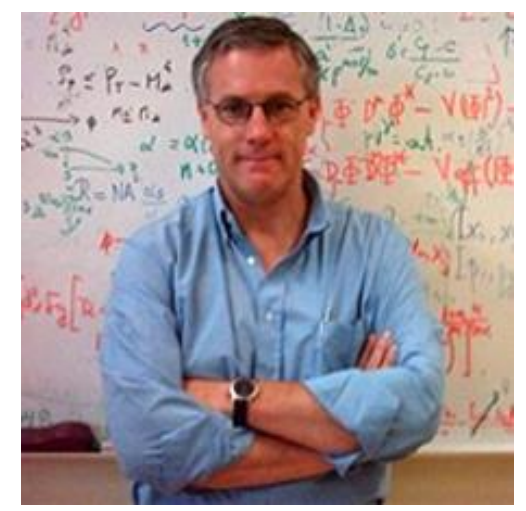

Orfeu Bertolami nasceu em São Paulo, Brasil, em 1959. Licenciado em Física pela Universidade de São Paulo em 1980, obteve o mestrado no Instituto de Física Teórica em São Paulo em 1983, o Grau Avançado em Matemática na Universidade de Cambridge no Reino Unido em 1984 e o doutoramento em física teórica na Universidade de Oxford em 1987. Desenvolveu actividades de investigação no Institut für Theoretische Physik em Heidelberg, Alemanha, no Centro Europeu de Investigação Nuclear (GERN) em Genebra, na secção de Turim do Istituto Nazionale de Fisica Nucleare e na Universidade de Nova Iorque. Foi, de 1991 a 2010, professor no Departamento de Física do Instituto Superior Técnico e é actualmente Professor Catedrático no Departamento de Física e Astronomia da Faculdade de Ciências da Universidade do Porto. Publicou cerca 330 artigos científicos, em livros, jornais, actas de conferências, 19o dos quais em revistas especializadas com arbitragem nas áreas da astrofísica, cosmologia, física e propulsão espacial, gravitação clássica e quântica, teorias das cordas quânticas e sobre o Sistema Terrestre. Já apresentou cerca de seis dezenas de palestras convidadas em conferências internacionais e mais de duas centenas de seminários especializados em universidades e centros de investigação na Europa, Rússia, Coreia do Sul, China, Japão, Brasil, Argentina, Chile e nos Estados Unidos. Tem participado em actividades de divulgação apresentando muitas dezenas de palestras sobre temas como a unificação das interacções fundamentais da Natureza, o Big Bang, a estrutura em larga escala do Universo, as explosões de raios gama, a origem da vida, ciência e literatura, a vida e a obra de Albert Einstein e Galileo, o Sistema Terrestre e sobre o Projecto Casa Comum da Humanidade. Foi galardoado com o terceiro prémio da Gravity Research Foundation dos Estados Unidos em 1999, com o Prémio União Latina de Ciência em 2001, o Prémio Universidade Técnica de Lisboa/Santander Totta de excelência científica nas áreas de Biofísica e Física em 2007, e com a menção "Outstanding Referee” da American Physical Society em 2013. Colabora em projectos internacionais sobre a matéria e a energia escura, física fundamental no espaço e sobre o Sistema Terrestre. Foi membro do Galileo Science Advisory Committee da Agência Espacial Europeia.de 2008 a 2013. É autor do "Livro das Escolhas Cósmicas", publicado pela Gradiva em 2006, uma narrativa da história da física do Universo da antiguidade até os nossos dias. É co-autor, com Martin Tajmar, do texto sobre um putativo controle da gravitação para fins de propulsão, publicado pela Agência Espacial Europeia em 2002; é co-autor e co-organizador do livro "Do Big Bang ao Homem" e do livro texto "Seis Breves Apontamentos de Cosmologia Contemporânea" escrito em co-autoria com Jorge Páramos, publicados em 2015 e 2016, respectivamente pelas Edições da Universidade do Porto. 


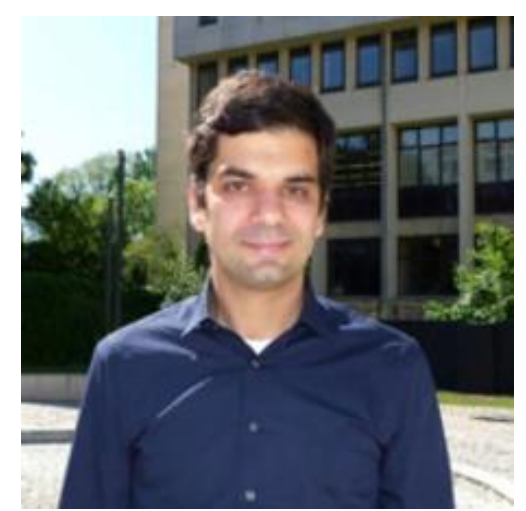

Frederico Francisco (1986) é natural de Cascais, Portugal, e fez a sua formação em Engenharia Aeroespacial no Instituto Superior Técnico da Universidade de Lisboa, tendo concluído o mestrado em 2009. Prosseguiu os estudos na mesma instituição com o doutoramento em Física obtido em 2014. A sua tese de doutoramento com o título "Anomalias de Trajectória em Sondas Interplanetárias" recebeu o prémio "Springer Theses" da SprinerVerlag e foi publicada em livro pela mesma editora. Como parte importante deste trabalho inclui-se o desenvolvimento do método de cálculo de acelerações de origem térmica que permitiu resolver a "Anomalia da Pioneer", problema que esteve em aberto durante cerca de 15 anos. A aplicação destes métodos a outras sondas no sistema solar, com a importância que tem enquanto teste à Relatividade Geral, valeu-lhe também a atribuição da Medalha Zeldovich 2018 pela Academia Russa de Ciências e a COSPAR (Commission on Space Research). Actualmente é bolseiro de pós-doutoramento na Faculdade de Ciência da Universidade do Porto, onde também é docente. Além da continuação da linha de investigação principal no domínio das ciências do espaço, tem também desenvolvido algum trabalho em áreas mais diversas como o transporte ferroviário ou a sociologia da ciência. Está agora também envolvido no desenvolvimento de um modelo físico para o Sistema Terrestre. Tem 10 artigos publicados em revistas internacionais com arbitragem científica, 1 livro técnico publicado por editora internacional, 4 publicações em actas de conferências internacionais e 2 capítulos em livros de interesse geral publicados em Portugal, além de várias apresentações orais por convite e alguns artigos de opinião em jornais de circulação nacional. 



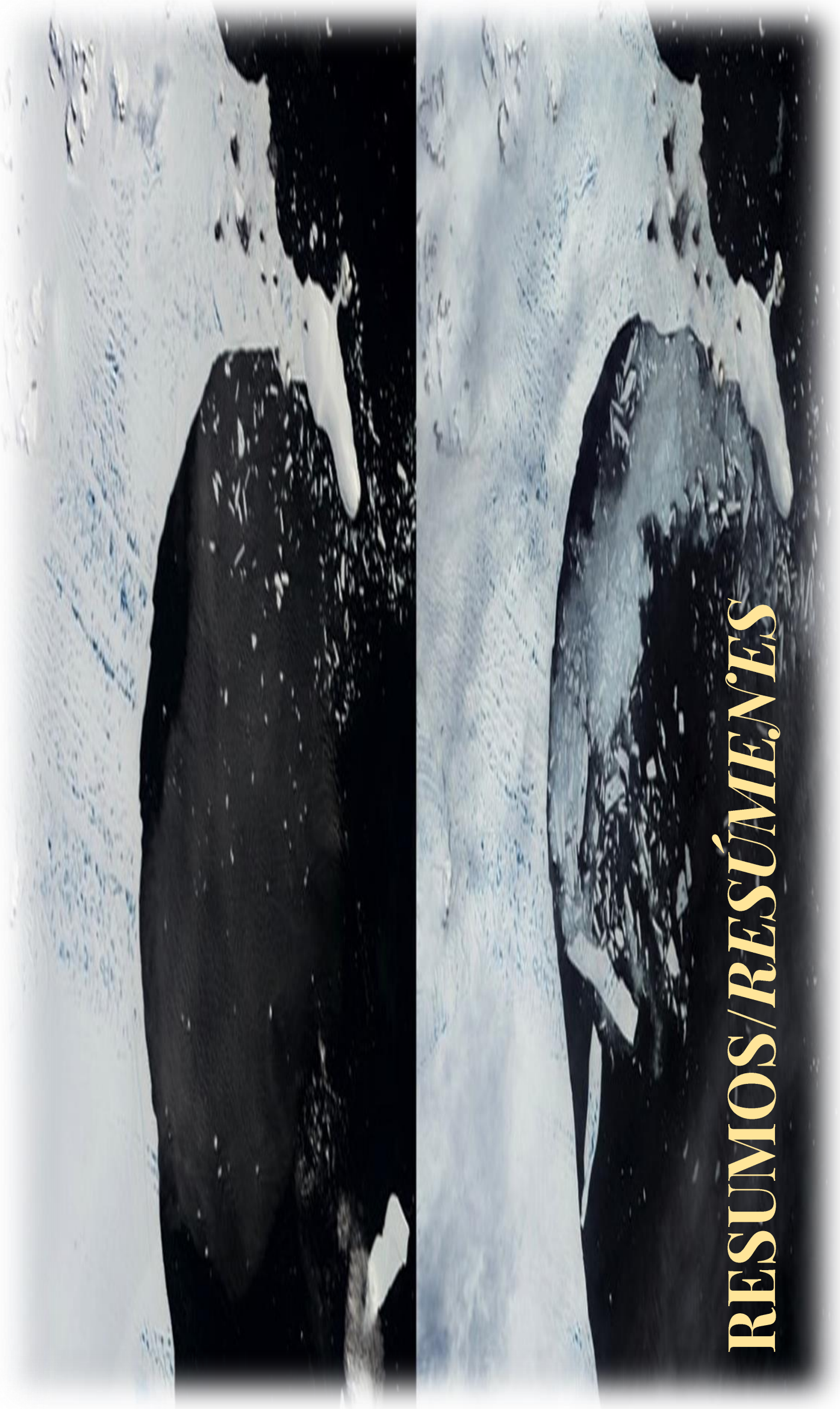




\title{
Claudia de Castro Andrade
}

\author{
UNIVERSIDADE DO ESTADO DO RIO DEJANEIRO
}

\section{Aspectos filosóficos do Antropoceno: o lugar da transmissão cultural em nossas representações simbólicas}

Palavras-Chave: transmissão cultural, antropoceno, qualia, comportamento

Compreender qualidades introspectivas, como sensações, julgamentos, decisões e memória, enquanto um conjunto de representações exclusivamente determinadas por uma intencionalidade cultural e artificialmente construída, além de negligenciar as inegáveis condições fisiológicas que as orientam, causa uma dicotomia irresponsável entre aspectos culturais e biológicos.

O mesmo vale para o contrário quando se desconsidera o papel da seleção e transmissão culturais no desempenho destas qualidades.

Obviamente que essas qualidades são decorrentes de áreas neurofisiologicamente ativadas, mas nem por isso podemos recusar o enfoque antropológico que os rodeia nem rejeitar suas propriedades fenomenológicas. Em outras palavras, defini-las como sendo o resultado de condições especificamente fisiológicas de áreas especializadas do cérebro não nos autoriza uma concepção orgânica e geneticamente fisicalista que recusa o papel seletivo das experiências vividas, das informações coletadas, da capacidade de aprender, da transmissão cultural (vertical, por meio de grupos hereditários, e horizontal, através de grupos sociais) e do impacto desses fatores na formação de nossa subjetividade ao longo do tempo.

Os estudos de Cavalli-Sforza, por exemplo, mostram como os artefatos tecnológicos desenvolvidos por nossos ancestrais influenciaram, contribuíram e moldaram nossas representações do mundo sendo, vale lembrar, fundamentais para nossa adaptação e sobrevivência.

Assim, qualidades introspectivas vão além de condições físicas quando entendemos que a participação da experiência, do aprendizado e da cultura e contribuíram de modo seletivo e crucial para nosso desenvolvimento.

Assim, os estados subjetivos e introspectivos (do latim pl. qualia) de nossa experiência consciente foram fundamentais no processo evolutivo e, por extensão, na formação de nossas escolhas e decisões mediante o contexto e as situações vividas por nossos ancestrais e, o aprimoramento dessas escolhas e decisões, foram determinantes para a relação entre o organismo e seu meio, pois decisões baseadas em um somatório de vantagens foram inegavelmente responsáveis pela adaptação e sobrevivência de nossa espécie. 
Assim considerando-se a interferência do processo de evolução natural e cultural e das informações recebidas que definiram nossas representações simbólicas e subjetivas entende-se ao mesmo tempo importância e necessidade de não refutarmos os qualia como parte do domínio da vida.

Nesse sentido, a forma como buscamos dominar a natureza e nos relacionarmos com nossos semelhantes e com o mundo, o qual revela um novo período histórico denominado Antropoceno, pode ser entendido como sendo influenciado pela forma como culturalmente representamos o mundo e por outro lado pelo retorno externo que recebemos dele.

\section{Nota curricular:}

Doutoranda em Filosofia pela Universidade do Estado do Rio de Janeiro (UERJ) e professora de filosofia do Estado do Rio de Janeiro. Bacharelado e Licenciatura em Filosofia pela Universidade do Estado do Rio de Janeiro (UERJ). Mestrado em História das Ciências, das Técnicas e Epistemologia pela Universidade Federal do Rio de Janeiro (UFRJ). Pós-graduação em Neuropsicologia, pelo Instituto de Neurociências Aplicadas (INA). Iniciação Científica na Faculdade de Educação da UERJ (PROPED - Programa de Pesquisas em Educação da Faculdade de Educação da Universidade do Estado do Rio de Janeiro / UERJ). 


\section{Anabela Carvalho \\ UNIVERSIDADE DO MINHO}

\section{Envolvimento político com as questões ambientais e a agenda das ciências sociais e humanas}

Palavras-Chave: cidadania; alterações climáticas; espaço mediático; esfera pública

A enorme escala da actual crise ambiental tem-se tornado cada vez mais evidente. Em particular, os impactos das alterações climáticas sobre os sistemas sócio-ecológicos constituem uma ameaça sem precedentes na história humana. Tal como a ameaça, o nível do desafio para a acção no sentido de mitigação das alterações climáticas é inédito. Como tal, nos últimos anos têm sido propostos vários conceitos para designar as mudanças que é necessário iniciar para construir sociedades sustentáveis, tais como a 'grande transição' (NEF, 2010), a 'grande transformação' (WBGU, 2013) e 'respostas transformativas' (Gillard et al., 2106). O que estes conceitos procuram veicular é a ideia de que será necessário levar a cabo mudanças estruturais a muitos níveis, incluindo o económico, o sócio-cultural e o político, ou seja que não há respostas fáceis ou simples que resultem de novas tecnologias ou de 'pequenas mudanças' de comportamento.

A extensão das transformações necessárias levanta múltiplas questões: quem, de forma explícita ou não, vai liderar esses processos? Como serão as decisões tomadas? Com base em que valores/critérios? Tudo isto apela a debates verdadeiramente democráticos em que sejam consideradas diferentes necessidades, visões e propostas, bem como a um aumento da transparência nos processos de decisão.

Porém, o que se vem verificando é que muitos dos processos em torno das alterações climáticas têm sido despolitizados (Maeseele, 2015), no sentido em que são retirados da esfera do debate para a esfera da gestão técnica dominada por elites. Neste âmbito, o cidadão é predominantemente posicionado como espectador e não como actor da política das alterações climáticas. Porém, o envolvimento dos cidadãos nestas questões, para além de um direito, será um requisito para aumentar o pluralismo.

Neste contexto, nos próximos anos, a investigação em ciências sociais e humanas deverá focar-se numa série de questões fundamentais relacionadas com a cidadania ambiental, ou seja, a construção de uma postura activa, exigente e responsável relativamente às transformações para a sustentabilidade. Tais formas de cidadania requererão um envolvimento político (Carvalho, van Wessel \& Maeseele , 2017), no sentido de participar e ter voz nos debates, e 
formas de agência cidadã que estão muito para além das mudanças de comportamento que são actualmente sugeridas por uma boa parte dos discursos dominantes.

Baseando-se em vários estudos empíricos, esta comunicação analisará vários tipos de discursos em torno das alterações climáticas, presentes nos media convencionais e noutras esferas públicas, relativamente às mudanças necessárias e aos papéis que os cidadãos podem desempenhar e discutirá possibilidades de investigação futura.

\section{Nota curricular:}

Anabela Carvalho (PhD, University College London) é Professora Associada no Departamento de Ciências da Comunicação da Universidade do Minho. A sua investigação centra-se nos domínios da comunicação e ambiente, comunicação e ciência, e comunicação e envolvimento politico, com particular incidência no tema das alterações climáticas. É autora e/ou organizadora de livros como As Alterações Climáticas, os Media e os Cidadãos (2011) e Climate Change Politics: Communication and Public Engagement (com T.R. Peterson; 2012), para além de cerca de uma centena artigos científicos e capítulos de livros. É actualmente 'Associate Editor' da revista Frontiers in Communication: Science and Environmental Communication. 


\section{António Carvalho, Ana Raquel Matos \& Vera Ferreira}

UNIVERSIDADE DE COIMBRA

\section{As políticas ontológicas do Antropoceno}

Palavras-Chave: política ontológica, política material, movimentos sociais, tecnologias emergentes

O Antropoceno tem sido alvo de uma extensa reflexão académica que suspende as barreiras clássicas entre as "duas culturas". Enquanto evento geológico e sociocultural, o Antropoceno tem suscitado um crescente interesse no âmbito da literatura das ciências sociais e dos Estudos de Ciência e Tecnologia (STS), gerando abordagens metodológicas e teóricas que privilegiam a estreita interconexão entre humanos e não-humanos.

Os STS registaram o que que habitualmente se designa enquanto uma "viragem ontológica", que coloca em causa o excepcionalismo humano e atribui uma dimensão política aos dispositivos e opções tecnológicas e materiais. O Antropoceno tem-se assumido enquanto conceito catalisador de novas formações sociais, políticas, estéticas, tecnológicas e artísticas que podem assumir diversos contornos ontológicos e políticos, desde a ecologia profunda, a geoengenharia e o pós-humanismo.

Reconhecendo a diversidade ontológica das "respostas" ao Antropoceno, nesta comunicação iremos explorar três estudos de caso que apresentam respostas - por vezes divergentes - para lidar com os desafios das alterações climáticas: o movimento Transição, um dispositivo Grassroots que visa a transição para sociedades de baixo carbono ao nível local, influenciado em larga medida por uma abordagem agrícola e filosófica associada à permacultura; políticas europeias em torno da descarbonização do sistema energético Europeu, nomeadamente o Roadmap 2050, que visa uma redução de aproximadamente 85\% de emissões de CO2 até 2050 em comparação com 1990; tecnologias emergentes frequentemente designadas como Geoengenharia, nomeadamente a solar radiation management (SRM).

O objetivo deste exercício de mapeamento ontológico é a identificação de distintas temporalidades, políticas materiais, formas de subjetividade e de governação mobilizadas para fazer face ao Antropoceno, identificando como movimentos sociais, instituições e a comunidade científica recrutam uma diversidade de imaginários sociotécnicos nas suas respostas às alterações climáticas. Em particular, esta comunicação irá argumentar que os múltiplos dispositivos sociotécnicos mobilizados para responder ao Antropoceno também se manifestam em diferentes versões do "mundo", o que nos permitirá um 
diálogo com algumas propostas de Bruno Latour e Isabelle Stengers em torno dos conceitos de ontologia, diplomacia e cosmopolítica.

O material apresentado nesta comunicação surge no âmbito do projeto de investigação TROPO (2018-2012), financiado pelo FEDER e pela FCT, atualmente a decorrer no Centro de Estudos Sociais da Universidade de Coimbra e que visa problematizar a heterogeneidade ontológica do Antropoceno.

\section{Notas curriculares:}

António Carvalho é investigador no Centro de Estudos Sociais, onde coordena, enquanto PI, o projeto TROPO (2018-2021), financiado pela Fundação para a Ciência e a Tecnologia e que visa analisar as múltiplas ontologias do Antropoceno em Portugal. Previamente trabalhou como investigador em pós-doutoramento no Instituto de Higiene e Medicina Tropical da Universidade Nova de Lisboa (IHMT/NOVA), onde esteve envolvido na implementação da Research Fairness Initiative. Os seus interesses de investigação incluem afeto, teoria pós-humanista, ética de tecnologias emergentes, mindfulness e o Antropoceno.

Ana Raquel Matos é investigadora do Centro de Estudos Sociais, e CO-PI do projeto TROPO. As suas atuais áreas de investigação incidem em temas como "Democracia e Participação Pública", "Movimentos sociais e ação coletiva", "Participação dos/as cidadãos/ãs nos sistemas de saúde" e "Relação entre Ciência e Conhecimentos". Tem dedicado especial interesse à análise das ações de protesto enquanto mecanismos de participação cidadã em contextos deliberativos, sobretudo na área da saúde.

Vera Ferreira é investigadora júnior no Centro de Estudos Sociais, onde integra a equipa de investigação do Projeto TROPO. Frequenta o Doutoramento em Alterações Climáticas e Políticas de Desenvolvimento Sustentável no Instituto de Ciências Sociais e é mestre em Relações Internacionais pela Faculdade de Economia da Universidade de Coimbra. Os seus interesses de investigação incluem a relação entre capitalismo e alterações climáticas, o Antropoceno e a mobilidade humana no contexto das alterações climáticas. 


\section{Flávio Freitas}

UNIVERSIDADE FEDERAL DO MARANHÃO

\section{A relação entre homem e natureza no capítulo 1 de O Anti-édipo}

Palavras-Chave: Deleuze, Guattari, homem, natureza

O objetivo do presente trabalho consiste em explicitar o núcleo da relação entre homem e natureza tal qual está exposta no capítulo 1 de $O$ Anti-Édipo Capitalismo e esquizofrenia, volume 1 de Deleuze e Guattari, cujo título é "As máquinas desejantes". Para tanto, caracterizaremos o conjunto do projeto "Capitalismo e esquizofrenia", destacando o percurso que vai da teoria do desejo à teoria das multiplicidades. No momento seguinte, descreveremos as relações entre o problema fundamental da filosofia política e a produção social. Em seguida, apresentaremos o conceito de máquinas desejantes, bem como o de corpo sem órgãos. Por fim, explicitaremos o núcleo da relação entre homem e natureza. Postulamos essa relação ocorra mediante um círculo vitalista composto pela relação entre as noções de homo natura e homo história, a qual corresponde à produção do real, que por sua vez é, univocamente, homo natura na medida em que é homo historia, visto que homem e natureza não são dois termos colocados um diante do outro como uma contradição, mas são uma só e mesma realidade essencial.

\section{Nota curricular:}

Doutor em Filosofia com área de concentração em Estrutura e Gênese do Conceito de Subjetividade pela Universidade Federal de São Carlos (UFSGar), cuja linha de pesquisa é a subjetividade na filosofia da psicologia e da psicanálise, com estágio sanduíche pela Université Paris 1 - Panthéon Sorbonne. professor efetivo adjunto I DE no campus V e professor permamente do Programa de Pós-Graduação (nível mestrado) Interdisciplinar em Cultura e Sociedade da Universidade Federal do Maranhão - PGCult 


\section{Jane Guimarães}

UNIVERSIDADE DE ÉVORA

\section{A mecanosfera de Deleuze e Guattari}

Palavras-Chave: mecanosfera, tecnologia, ecologia, agenciamento

A mecanosfera, conceito proposto por Deleuze e Guattari nas obras que constituem a série sobre o Capitalismo e Esquizofrenia, tem como aspeto fundamental a constatação da ausência da distinção clássica entre as esferas do natural e artificial. "Não há biosfera, noosfera, por toda parte só há uma única e mesma Mecanosfera” (Deleuze/Guattari [1980], 1997: 86). Essa esfera das máquinas, onde não há dissociação entre a esfera do homem, demais seres, natureza e a dimensão técnica, é o principal ponto de articulação do pensamento de Deleuze e Guattari no que tange a ecologia. Em L'Anti-CEdipe Deleuze e Guattari afirmam que a questão não é confrontar o homem e máquina, natural e artificial, mas de pensar como essas peças heterogêneas podem se integrar numa composição.

O presente trabalho tem como proposta expor de que maneira o conceito de mecanosfera de Deleuze e Guattari pode contribuir para o debate em torno da relação entre os seres humanos e a natureza, contudo, de modo que essa discussão não passe pelo antropocentrismo, pela tecnofilia bem como pela tecnofobia.

Deleuze e Guattari, em consonância com a obra de Simondon, Bateson e Leroi-Gourhan, nos mostram em que condições os humanos são maquinações e em que condições estão humanos, máquinas e natureza no mesmo plano de articulação. Dessa maneira, sendo possível pensar outras formas de relação com a natureza que não seja a violência. Portanto, há no pensamento de Deleuze e Guattari a noção de que entre o humano, a máquina, demais seres e 0 ambiente existem muitos agenciamentos, trocas, sem, contudo, haver um privilégio do humano em relação aos demais seres nessas trocas.

O que não significa, portanto, um apego a um humanismo. Bem como, segundo as perspectivas expostas pelos autores, também não se trata de resguuardar a essência do humano. Não havendo, assim, espaço para um ponto de vista pós-humanista, pois este só é possível no interior de uma metafisica idealista antropocêntrica, como também observa Viveiros de Castro ao falar das correntes aceleracionistas e economodernistas (Viveiros de Castro, 2015: 10).

Logo, tomando a noção de mecanosfera como fio condutor, pretendo mostrar que caminhos Deleuze e Guattari abrem para o debate sobre as questões relacionadas a tecnologia e a natureza, como funcionam esses 
agenciamentos maquínico que nos falam os referidos autores e em que medida essas perspectivas são relevantes para a discussão em torno da ecologia e do antropoceno.

\section{Nota curricular:}

Graduada em Filosofia (2008) pela Universidade Federal de Ouro Preto. Mestre em EducaçãoFilosofia da Diferença (2012) pela Universidade Federal do Rio Grande do Sul. Atualmente bolsista da CAPES, doutoranda em Filosofia na Universidade de Évora com o tema da tese versando sobre a questão da tecnologia com Deleuze, Guattari e Simondon. 


\title{
Thomas Heyd
}

\author{
UNIVERSITY OF VICTORIA, CANADA
}

\section{El antropoceno y el contrato natural}

Palabras-Clave: contrato natural, contrato social, derechos de la naturaleza, cambio climático

La transformación de nuestras formas de vivir que son necesarias para hacer frente a un clima cambiante en el Antropoceno puede parecer un reto desmesurado, dado que la inercia de las culturas humanas. Los valores individuales, las normas sociales y las concepciones culturales globales generalmente conllevan resistencia al cambio, aunque éstos factores también pueden ser transformados. Aquí se explora la propuesta de Michel Serres para un nuevo "contrato natural", que se hace eco de las propuestas de los siglos XVII y XVIII para un "contrato social" de Hobbes, Locke y Rousseau. Si bien la idea de un contrato social dirige nuestra atención a la posible coherencia entre los intereses de diversos agentes autónomos humanos, la idea de un contrato natural apunta hacia la importancia de incorporar en nuestros esquemas de gobernanza 'el mundo' como un participante activo que cada vez más condiciona nuestras existencias. Se argumenta que, en la medida en que la idea de un contrato social tiene una aceptación amplia, tácita, y es parte de nuestro patrimonio cultural común, la idea de un contrato natural adquiere un grado de plausibilidad inicial substancial.

\footnotetext{
Nota curricular:

M.A., B.A. (Galgary), Ph.D. (Western Ontario). Lecionou nas Universidades de Calgary e Alberta, assim como na Alemanha e na Argentina. Bolseiro de investigação da Organization of American States, Centre for Studies in Religion and Society da University of Victoria, Japan Foundation, Australian National University e University of Calgary. Entre as suas publicações destacam-se: Encountering Nature: Toward an Environmental Culture (Ashgate 2007); Recognizing the Autonomy of Nature (CUP 2005); Aesthetics and Rock Art (Ashgate 2005). The Natural Contract: Old World vs. New World Perspectives, em Marrero H. (Ed), Transatlantic Landscapes: Environmental Awareness, Literature, and the Arts (2016); The sacred, the peopled land, and climate change em Hankard y Charlton (Eds), We Still Live Here: First Nations, the Alberta Oil Sands, and Surviving Globalism (2016); Art, Rock Art and Climate Change, com T. Lenssen-Erz, em Putová \& Soukup (Eds), The Genesis of Creativity and the Origin of the Human Mind (2015).
} 


\section{Hermes de Andrade Júnior}

UNIVERSIDADE CATÓLICA PORTUGUESA

\section{Logística Reversa: alguns aspectos sobre a aplicabilidade da política de resíduos sólidos no Brasil}

Palavras-Chave: logística reversa, política brasileira de resíduos sólidos, reciclagem, empresas brasileiras, redução de resíduos, imagem organizacional

A extração de matérias-primas da natureza tem enormes impactos ambientais associados, acrescendo os elevados consumos de água e energia implicados também no transporte, transformação e fabrico dos produtos. A evolução da quantidade de produtos disponíveis no mercado e da forma como estes são colocados à disposição do consumidor tem conduzido a um aumento significativo da produção de resíduos. A logística reversa (LR) é um instrumento de desenvolvimento econômico e social que permite a restituição dos resíduos sólidos ao setor empresarial para reaproveitamento em seu ciclo ou em outros ciclos produtivos, ou mesmo dando outra destinação final ambientalmente adequada. A LR é assunto recentemente estudado dentro da economia circular e extremamente importante para o contexto do antropoceno no tocante aos parâmetros dos "3Rs" (Redução, Reutilização e Reciclagem) onde pode-se, para além da amenização do impacto ambiental, gerar ganhos de imagem e de reputação empresarial e organizacional. A política dos 3 Rs consiste num conjunto de medidas de ação adotadas na Conferência da Terra realizada no Rio de Janeiro em 1992, bem como no $5^{\circ}$ Programa Europeu para o Ambiente e Desenvolvimento, de 1993. Aplica-se para todo o tipo de resíduos/efluentes sólidos, líquidos e gasosos. No Brasil, houve iniciativas ambientais neste sentido desde antes deste marco histórico, entretanto, por várias razões, a política nacional de resíduos sólidos brasileira (PNRS) levou quase duas décadas para passar por casas legislativas até ser aprovada como uma lei que protege o meio ambiente. Durante este período e após sua aprovação, fatores pró-ambientais levaram ao direito de transformar e criar protocolos, acordos e novas empresas no sentido de uma logística reversa ou de reversibilidade nos efeitos ambientais da cadeia de suprimentos. Este estudo objetivou apresentar aspectos da realidade empresarial brasileira no processo de implementação da PNRS como uma reflexão sobre a perspectiva de reciclagem de produtos e controle de resíduos sólidos e logística reversa. A PNRS está em fase de expansão corporativa, fazendo um balanço de oito anos desde a criação da lei (2010). Como alguns ramos da atividade empresarial 
brasileira ainda não tiveram a logística reversa regulada, nos próximos anos deve haver uma demanda muito maior para esse tipo de negócio reverso.

\begin{abstract}
Nota curricular:
Hermes Júnior é bacharel em relações internacionais e também em ciências militares no Brasil. Possui um mestrado em sociologia e um doutorado em saúde pública, com ênfase na sociedade e no meio ambiente. É professor e pesquisador há mais de 15 anos, docente em faculdades/universidades brasileiras em várias disciplinas e consultor ad hoc da CAPES/Brasil na área de cooperação internacional. Tem livro, capítulos e artigos publicados em revistas variadas. Desde 2017 faz um pós-doutorado na Universidade Católica, sendo pesquisador sênior do Centro de Estudos Filosóficos e Humanísticos da Universidade em Braga (CEFH/UCP). Desenvolve em Portugal, em parceria, estudos de resiliencia (identidade nacional e resiliencia nacional) e competência ambiental e no Brasil, estudos de locus de controle e de percepção da conservação ambiental em universitários.
\end{abstract}




\section{Isabel Ponce de Leão \& Wlodzimierz Szymaniak \\ UNIVERSIDADE FERNANDO PESSOA / UNIVERSIDADE JEAN PIAGET, CABO \\ VERDE}

\section{Angola / Luanda: a consciência do antropoceno em Mais um dia de vida Ryszard Kapuscinski}

Palavras-Chave: Kapuscinski, antropoceno, impacto, guerra

Quando Paul Crutzen sobrelevou a evidência do impacto humano no ambiente, mostrando que a sua interferência no planeta colocava em risco a própria sobrevivência da humanidade foi, posteriormente, contraditado pelo Manifesto Ecomodernista, que recusa a visão do ser humano enquanto destruidor da natureza, para defender que essa alteração da escala geológica do planeta poderia, através das novas tecnologias, corrigir danos ambientais. Assim, o referido Manifesto postula que a nova era do antropoceno poderá ser positiva se o poder económico, social e tecnológico for usado em função da melhoria de vida humana, da estabilização climatérica e da protecção da natureza.

Não vem ao caso discutir estas duas posições mas, sendo as cidades 0 exemplo mais visível do impacto humano, tentaremos, através da obra Mais um Dia de Vida de Ryszard Kapúscinski, notável repórter polaco que exerceu o jornalismo imersivo, e do filme homónimo de Raúl de la Fuente e Damian Nenow perspectivar o impacto sofrido em Angola / Luanda, transformada em cidade fantasma sitiada, quer pelo processo de descolonização quer pela sangrenta guerra civil que se seguiu.

\footnotetext{
Nota curricular:

Isabel Ponce de Leão é Professora Catedrática da Universidade Fernando Pessoa, Porto, e membro integrado do CLEPUL, coordenando do Polo do Porto. Como docente e investigadora tem colaborado com outras instituições de ensino superior, em Portugal, Brasil, e outros países europeus e africanos. Coopera, entre outras, com a Câmara Municipal do Porto, onde é deputada municipal e preside a Comissão de Toponímia. As suas áreas de investigação são a Literatura Portuguesa Contemporânea bem como as relações que esta estabelece com as artes plásticas, a $7 .^{\mathrm{a}}$ arte (interartes) e as ciências, e o jornalismo cultural. Nas suas publicações inscrevem-se cerca de 20 livros e mais de 200 artigos.
}

Wlodzimierz Szymaniak é Reitor da Universidade Jean Piaget de Cabo Verde. Tem 24 anos de serviço docente exercido em universidades europeias e africanas e experiência de gestão 
universitária e coordenação de equipas de trabalho no contexto intercultural. É tradutor, nomeadamente de Ryszard Kapuscinski, e domina 6 idiomas para além de crioulos e pidgins de origem portuguesa. Tem vasta obra publicada nos âmbitos das Literaturas HispanoAmericanas, das Ciências da Comunicação e, sobretudo, da Interculturalidade. 


\section{Sérgio Lira}

GREEN LINES INSTITUTE FOR SUSTAINABLE DEVELOPMENT

\section{Museus e periodização: já estamos no Antropoceno?}

Palavras-Chave: museus, periodização, antropoceno, exposição

Mesmo para quem disputa o conceito, a evidência de um período da História da Terra em que uma espécie - o Homo Sapiens - detém um poder inigualável, nunca antes atingido e potencialmente destruidor, é inevitável. Poder-se-á discutir a profundidade e o alcance de tal, mas a sua existência só a estúlticia tentará negar. Ora essa evidência, à imagem de tantas outras, há-de ter reflexos nos modelos e nas interpretações da realidade que os seres humanos constroem para se sentirem confortáveis ao olhar o (seu) Mundo: encontrar um esquema mental que lhes satisfaça a curiosidade e aplaque 0 búlicio intelectual perante o desconhecido ou o incompreensível pauta, de há muito, a Humanidade. Uma das formas de o fazer é criar nomenclaturas, outra periodizações. Olhar o presente exige categorias - Aristóteles que o diga - e olhar o passado demanda cronologia - agora que o paradigma não mais é o do tempo cíclico dos gregos antigos, mas sim o tempo linear de $\mathrm{St}^{\circ}$ Agostinho (ou de Marx....).

Os museus são um dos reflexos dessa categorização e dessa periodização - outros há, de maior ou menos monta, mas hoje interessa-nos este, o dos museus. Não há museu que não classifique, raro será o que não periodize. Na falta da primeira sentimo-nos desassossegadamente confusos, da segunda estranhamente perdidos. Pois sendo consabido que visitantes confusos ou perdidos não aproveitam da estada no museu, essas instituições tudo fazem para que tais estados d'alma não assaltem os visitantes, ao menos de forma contínua. A classificação não nos importa desta feita, antes a periodização: que baluartes cronológicos usam os museus de hoje? Em se tratando de museus de História Natural - daqueles em que o Antropoceno seria assunto de eleição com maior facilidade - está (já) o Antropoceno presente (como conceito, como período, como assunto de debate...?). Pretendemos olhar os museus actuais, ao menos em alguns dos seus exemplos mais significativos, e fazer estas perguntas, reservando-nos ainda algum espaço para reflectir acerca das respostas que obtivermos. 


\section{Nota curricular:}

Licenciado em História e Mestre em História Medieval pela Universidade do Porto. PhD em Museum Studies pela University of Leicester (U.K.) reconhecido com grau de "Doutor" pela Universidade do Porto. Foi Professor Associado na Universidade Fernando Pessoa. É sócio fundador, presidente da direcção e investigador responsável no Green Lines Institute for Sustainable Developent. Investigador integrado do CLEPUL e membro da coordenação do pólo do Porto daquele centro de investigação. Coordenador de projectos museológicos e museográficos nacionais e internacionais. Áreas de investigação científica e trabalho aplicado: Museologia e Museografia; Património; Consumos Culturais. 


\section{Cynthia Luderer \\ UNIVERSIDADE DO MINHO}

\section{Entre memórias e ideologias: um nebuloso cenário para as escolhas alimentares}

Palavras-Chave: ideologias, memórias, alimentação, sustentabilidade

Dentre as recentes mensagens relacionadas à sustentabilidade e divulgadas pelos meios de comunicação estão as que anunciam a possibilidade de haver, num futuro próximo, uma crise alimentar, a qual estaria relacionada ao crescente número de habitantes no planeta e à mudança climática. Nesse prisma, cabe relacionar as informações sobre a possibilidade da comercialização de carne sintética, os apelos em prol de uma revolução vegana ou, ainda, a dieta planetária, recém-sugerida por cientistas, a qual tem o propósito de amenizar o cenário nebuloso que se enreda no entorno da comida. Relacionadas aos discursos da sustentabilidade, essas mensagens convocam o consumidor a assumir seu papel de cidadão por meio de novas condutas alimentares, expondo a ele uma suposta parcela de culpa e responsabilidade, relacionadas ao propósito de salvar o planeta. Ou seja: no que se refere às suas escolhas alimentares, ele é convidado a ter uma visão crítica da vida social. Por sua vez, há outras mensagens midiatizadas sobre o alimento, como as relacionadas ao gênero das receitas culinárias, as quais oferecem uma relação poética ou utópica com os ingredientes, quer pela via dos discursos mnêmicos ou dos da saúde. Essa gama de mensagens interconectadas com o alimento enuncia uma relação entre o passado e o futuro, entre a ideologia e a utopia, entre a opção e a obrigação, entre desejo e renúncia ou, ainda, entre as possibilidades das escolhas do Eu e as do Outro. Ao pensar que os impasses possam ser percebidos como sintomas do mal-estar contemporâneo, este estudo está proposto a discutir nesse âmbito, sobre o papel que ocupam essas mensagens relacionadas às condutas alimentares.

Com o objetivo de analisar os discursos veiculados que insinuem esses impasses entorno da alimentação, foram selecionados e conferidos dois grupos de notícias: um relacionado às recentes notícias publicadas no início de 2019, as quais tiveram repercussão internacional - a da dieta da saúde planetária e a da carne sintética e sua possibilidade de comercialização-; e outro relacionado ao gênero das receitas culinárias e, para tanto, optou-se pelas seis edições da revista portuguesa Sabe Bem, veiculadas em 2018, por se tratar de uma publicação que dita, com veemência, a favor da Dieta Mediterrânica e sua condição patrimonial. As análises foram desenvolvidas com base nos princípios 
da Análise Crítica do Discurso, sendo os conceitos de Ideologia e Utopia amparados nas premissas de Paul Ricoeur. No que se refere às premissas sobre o mal-estar contemporâneo, focou-se nos conceitos psicanalíticos lacanianos.

\section{Nota curricular:}

Doutora em Comunicação e Semiótica pela Pontifícia Universidade Gatólica de São Paulo, Brasil, com estágio desenvolvido na Universitat Rovira i Virgili, Espanha, junto ao programa de Antropologia da Alimentação. Há mais de dez anos dedica-se aos estudos sobre o cenário midiático entorno da alimentação e está a desenvolver um pós-doutoramento com vistas a essa temática na Universidade do Minho, com uma pesquisa vinculada ao Centro de Estudos de Comunicação e Sociedade. Na docência, atuou no Brasil em cursos superiores da área de Pedagogia, Gestão e Hospitalidade. 


\section{Ana Raquel Matos, António Carvalho \& Vera Ferreira UNIVERSIDADE DE COIMBRA}

\section{Antropoceno e alterações climáticas no Parlamento: atores, imaginários e pós-política no discurso político português (1990- 2018)}

Palavras-Chave: alterações climáticas, Portugal, debates parlamentares, teoria ator-rede

Amplamente discutido enquanto objeto da política internacional, a complexidade do Antropoceno, em especial no que diz respeito ao fenómeno das alterações climáticas, tem exigido um vasto debate em torno da necessidade de uma estreita articulação intergovernamental, à escala global, a partir de compromissos idealmente vinculativos.

Assumindo a urgência em torno deste debate pelas consequências implicadas para toda a humanidade, esta comunicação centra-se na análise do discurso político português sobre alterações climáticas a partir das narrativas veiculadas nos debates parlamentares entre 1990-2018. Este trabalho discute, assim, a evolução dos principais argumentos dos/as deputados/as dos diferentes partidos com assento parlamentar ao longo das últimas três décadas em torno desta questão, identificando as principais causas que vêm sendo apontadas para o problema, as diferentes dimensões e atores (nacionais e internacionais) recrutados no âmbito das estratégias argumentativas e as possíveis propostas/soluções avançadas em contexto nacional para enfrentar este problema.

Partindo da teoria do ator-rede enquanto referencial teóricometodológico para analisar os debates parlamentares, esta comunicação irá explorar os vários imaginários sociotécnicos subjacentes às intervenções parlamentares sobre alterações climáticas no contexto português. Será mapeada a complexa rede de relações entre humanos e não humanos, suas associações e dissociações, os dispositivos científicos e as múltiplas entidades que são recrutadas nos processos argumentativos relativos à mitigação e adaptação em torno das alterações climáticas.

Os resultados provisórios indicam que existe uma linha argumentativa transversal a estes debates, que é o consenso que só um estreito esforço de cooperação sem precedentes entre Estados poderá permitir a mitigação dos efeitos devastadores das alterações climáticas, o que realça a dimensão "póspolítica" dos imaginários sociotécnicos do Antropoceno. 


\section{Notas curriculares:}

Ana Raquel Matos é investigadora do Centro de Estudos Sociais, e CO-PI do projeto TROPO. As suas atuais áreas de investigação incidem em temas como "Democracia e Participação Pública", "Movimentos sociais e ação coletiva", "Participação dos/as cidadãos/ãs nos sistemas de saúde" e "Relação entre Ciência e Conhecimentos". Tem dedicado especial interesse à análise das ações de protesto enquanto mecanismos de participação cidadã em contextos deliberativos, sobretudo na área da saúde.

António Carvalho é investigador no Centro de Estudos Sociais, onde coordena, enquanto PI, o projeto TROPO (2018-2021), financiado pela Fundação para a Ciência e a Tecnologia e que visa analisar as múltiplas ontologias do Antropoceno em Portugal. Previamente trabalhou como investigador em pós-doutoramento no Instituto de Higiene e Medicina Tropical da Universidade Nova de Lisboa (IHMT/NOVA), onde esteve envolvido na implementação da Research Fairness Initiative. Os seus interesses de investigação incluem afeto, teoria pós-humanista, ética de tecnologias emergentes, mindfulness e o Antropoceno.

Vera Ferreira é investigadora júnior no Centro de Estudos Sociais, onde integra a equipa de investigação do Projeto TROPO. Frequenta o Doutoramento em Alterações Climáticas e Políticas de Desenvolvimento Sustentável no Instituto de Ciências Sociais e é mestre em Relações Internacionais pela Faculdade de Economia da Universidade de Coimbra. Os seus interesses de investigação incluem a relação entre capitalismo e alterações climáticas, o Antropoceno e a mobilidade humana no contexto das alterações climáticas. 


\section{João Ribeiro Mendes}

UNIVERSIDADE DO MINHO

\section{O antropoceno como objeto-fronteira}

Palavras-Chave: antropoceno, conflito de narrativas, objeto-fronteira (boundary-object)

O vocábulo "antropoceno" foi formalmente cunhado em 2000, pelo químico atmosférico holandês Paul Crutzen e pelo limnologista estadunidense Eugene Stoermer, para dar expressão à ideia de que entrámos já num novo capítulo da história do nosso planeta em que a espécie humana se converteu num agente geológico e geomórfico fundamental, detentor do poder de provocar efeitos geofísicos similares ou superiores aos das forças da natureza globais.

Em 2002 sozinho e em 2003 com o químico estadunidense Will Steffen, o mesmo Paul Crutzen reitera que "a Terra opera agora num estado nãoanálogo". Isso significa, no seu entender, que o antropoceno: (a) introduziu uma rutura com o holoceno, o período de cerca de 11.700 anos de relativa estabilidade climática que permitiu a emergência das civilizações conhecidas; (b) resultou acidentalmente de um processo evolutivo natural; (c) tem como principal agente causador a Humanidade (Anthropos); (d) exibe tendência para um aumento dos riscos catastróficos globais que pode ser contrariada com projetos de geoengenharia e administração tecnocrática (governo de peritos) do sistema terrestre.

Esta narrativa - "relato histórico de um conceito, dos seus motivos ou razões e consequências, que motiva, orienta e legitima decisões e ações" (Lidskog \& Waterton 2018) - considerada dominante e também denominada "narrativa científica" ou "narrativa naturalista" do antropoceno, tecida no âmbito das ciências naturais, em particular das ciências do sistema terrestre, tem sido fortemente criticada por cientistas sociais e académicos das humanidades.

Reivindicam alguns que atribuição da responsabilidade pela situação atual à Humanidade inteira serve propósitos ideológicos de ocultação de diferentes responsabilidades históricas de distintos povos e nações. Sustentam outros que o antropoceno não surgiu naturalmente nem acidentalmente, mas é fruto da particular ideologia económica do capitalismo e do modo como estrutura a relação homem-natureza. Entendem ainda outros que é muito temerário prosseguir projetos de engenharia à escala planetária, não somente porque não dispomos do conhecimento suficiente para o seu controlo, como 
fariam correr riscos irreversíveis e baseiam-se no suposto muito questionável de que os males provocados pela tecnologia podem ser reparados pela tecnologia. Consideram ainda alguns que o nosso planeta é um sistema demasiado complexo para que possamos ter uma visão linear acerca do seu futuro, que de se afigura claramente crescentemente instável, indeterminado e imprevisível.

Perante este "conflito de narrativas" acerca do antropoceno, instaurado, em boa medida, por diferentes interpretações do conceito feitas a partir de distintas tradições de inquérito independentes, nomeadamente as das ciências naturais, engenharias, ciências sociais e humanidades, importa ou mesmo urge pensar em criar um mecanismo de coordenação do trabalho epistémico que se encontra a ser levado a cabo por investigadores afetos a tais distintas tradições de inquérito independentes.

É propósito desta comunicação explorar a ideia de "objeto-fronteira" (boundary object), enquanto dispositivo de coordenação do trabalho científico, introduzida pelos sociólogos Susan Star e James Griesemer no artigo "Institutional ecology, "translations", and boundary objects: amateurs and professionals" (1989) e decortinar em que medida pode ter aplicabilidade e ser fecunda no âmbito dos Estudos do Antropoceno.

\footnotetext{
Nota curricular:

João Ribeiro Mendes é Professor Auxiliar do Departamento de Filosofia da Universidade do Minho (UM). Leciona cursos de graduação e pós-graduação em Epistemologia, Filosofia da Giência, Filosofia da Tecnologia e Giência, Tecnologia e Sociedade. Obteve o doutoramento em Lógica e Filosofia Moral na Universidade de Santiago de Compostela. É diretor-adjunto do Departamento de Filosofia da UM desde 2014. É investigador e atual diretor do Centro de Ética, Política e Sociedade da UM. É autor e coautor de diversos livros académicos, atas e volumes de revistas académicas, além de ter publicado inúmeros artigos, resenhas críticas e capítulos de livros em português e inglês sobre diversos temas. É editor da revista Ethics, Politics \& Society. A fournal in Political and Moral Philosophy e foi editor da revista Diacrítica-série Filosofia e Cultura, uma publicação nas Humanidades, entre 2012 e 2016. É o investigador principal de dois projetos de pesquisa em curso: (a) SFIDA: Soluções Filosóficas Inovadoras para o Desafio Antropoceno (2018-2022); (b) Engenheiros Reflexivos - Uma Abordagem Crítica da Tradição do Pensamento da Engenharia sobre Tecnologia (2014-2020). Foi professor visitante na Universidade Jagiellonian de Cracóvia (Polônia) em 2014, da Universidade Sun Yat-Sen (Zhuhai, China) em 2018, da Middle-East Technical University de Ancara (Turquia), da Pontificia Universidad Católica del Perú em Lima (Perú) e da Sophia University em Tóquio (Japão) em 2019.
} 


\section{Maria do Carmo Mendes}

UNIVERSIDADE DO MINHO

\section{O Pós-antropoceno em Oryx and Crake de Margaret Atzood}

Palavras-Chave: Atwood (Margaret), pós-antropoceno, Oryx and Crake

Na trilogia MaddAddam (constituída pelos romances Oryx and Crake 2003 -, The Year of the Flood - 2009 - e MaddAddam - 2013), a escritora canadiana Margaret Atwood retrata um universo pós-apocalíptico despoletado pela interferência do humano nos ecossistemas.

Esta comunicação, centrada no primeiro romance a trilogia, tem assim como principais propósitos: 1) Mostrar as perturbações quase irreversíveis provocadas por um grupo de cientistas nos ecossistemas; 2) Reconstruir os mecanismos apresentados pela narradora para identificar um poder científico e tecnológico sem precedentes para extinguir a biosfera; 3) Comentar a posição otimista que marca cada uma das obras e que vai além do sentido de catástrofe contido no Antropoceno.

\section{Nota curricular:}

Professora e investigadora do Instituto de Letras e Ciências Humanas da Universidade do Minho. Vicepresidente do ILCH e presidente do Conselho Pedagógico do mesmo Instituto. Especialista em Literatura Comparada e em Literatura Portuguesa Moderna e Contemporânea, tem publicado ensaios sobre: escritores de língua portuguesa; escritores de língua inglesa; mito de Don Juan; Ecocrítica; Literatura Fantástica e Policial; influências clássicas na Literatura Portuguesa Contemporânea; Diálogos entre a Literatura Portuguesa e as Literaturas Hispano-Americanas. As suas publicações mais recentes são os livros Don fuan(ismo): o mito (2014), Artes e Ciências em Diálogo (coordenação com Isabel Ponce de Leão e Sérgio Lira -2015), Idades da Escrita: estudos sobre a obra de Agustina Bessa-Luís (2016) e Humores e Humor na Obra de Agustina Bessa-Luís (coordenação com Isabel Ponce de Leão 2017) e Ecocriticism 2018. Literature, Arts and Ecological Environment (coedição com Isabel Ponce de Leão e Sérgio Lira - 2018). 


\section{Rui Paes Mendes \\ UNIVERSIDADE DO PORTO}

\section{As pestes em tempo do primado da ciência}

Palavras-Chave: pestes, pandemias, tecnociência, ambivalência tecnocientífica

Nas últimas décadas a humanidade tem assistido à eclosão de diversas ameaças de doenças declaradas pandémicas. Os vírus da Gripe A, do Ébola ou o Zika, entre outros, representaram preocupações que ocuparam (e ocupam) os órgãos de comunicação social, na opinião pública e nos decisores políticos, conjugando esforços para a contenção desses e de outros vírus com grande poder letal.

Esta conjuntura pandémica que a nossa civilização e o nosso tempo têm vivido, mais não é do que uma das faces de um problema complexo que assenta raízes fundas no desenvolvimento tecnológico e social. Nos últimos duzentos anos, desde o dealbar da Revolução Industrial, o Homem tem quebrado as barreiras do espaço e do tempo. Continentes que outrora eram terra ignota, estão hoje profusamente mapeados; povos que estavam literalmente a anos de distância, encontram-se hoje tão próximos quanto o tempo que um voo intercontinental demore.

A vertigem do desenvolvimento tecnológico a que assistimos teve (tem) consequências. Essa tecnologia, obra do engenho humano e que permitiu a qualidade de vida de metade da população mundial e se tornou símbolo do progresso e das conquistas tecnológicas da humanidade é a mesma que mostra que esse mesmo engenho, esse mesmo progresso, é a maior ameaça à sobrevivência da humanidade e que um dos seus grandes inimigos tem uma dimensão microscópica.

\footnotetext{
Nota curricular:

Rui Paes Mendes é investigador do Centro de Estudos de Geografia e Ordenamento do Território/FLUP (CEGOT), onde tem como áreas de investigação preferencial o estudo das cidades africanas, em especial da África de líng̉ua portug̉uesa, tendo publicado diversos artigos sobre o tema. É licenciado em Relações Internacionais e licenciado em Geografia. Doutor em Geografia Humana, pela Faculdade de Letras da Universidade do Porto (FLUP), com uma tese intitulada "A Cidade Colonial e a Estruturação do Território em Moçambique - A evolução urbana de Lourenço Marques/Maputo, Beira, Nampula e Porto Amélia/Pemba".
} 


\section{Marcelo Moraes \& Mariane Bitteti \\ UNIVERSIDADE DO ESTADO DO RIO DE JANEIRO}

\section{Ontologia Ubuntu: Natureza ser-com Homem}

Palavras-Chave: ontologia; Ubuntu, natureza, antropoceno

Há inúmeras concepções sobre homem, natureza e sobre a relação homem-natureza ao longo da história da filosofia e diante do desenvolvimento da ciência. Cosmologias que se produzem como pensamentos vinculados a determinados modos de ser e existir num dado contexto temporo-espacial. Quando buscamos compreender tais perspectivas, o fazemos muito mais como uma reflexão sobre o pensamento de uma época.

Parece-nos, no entanto, que a perspectiva do Antropoceno quer se revelar mais um estado do real, algo dado como concretude, algo que revela o resultado de um conjunto de relações predatórias do homem, ser genérico, diante de uma natureza cada vez mais mercantilizada, tratada como recurso ou matéria-prima e base para a acumulação do capital em escalas cada vez mais ampliadas, e menos como um pensamento. De tal maneira que, se o modo de ser e existir contemporâneos produziu uma dada realidade socioambiental, precisamos entender o sentido cosmológico do Antropoceno e buscar apreender outras narrativas que sejam potências para outros modos de ser.

A nossa referência de um outro modo de ser-existir-com será aqui mediada pela ética ubuntu, do povo Banto da África, que, portadora de um certo espírito africano de ser e de existir, no qual a natureza é sempre o outro que me complementa, e que eu só sou, se ela é, consegue romper com a lógica ocidental de que preciso denominar o outro, controlar e conquistar, para eu ser eu. Nesse caso porque supomos que há um risco de uma possível leitura antropocena do mundo que precisamos evitar, uma vez que podemos cair novamente na centralização do homem, homem este que se distingue da natureza, compreendendo a natureza como um outro que, quando não pode ser controlada, pode ser cuidada.

O risco desse movimento é de compreender a natureza como um outro, não como um mesmo em si, como uma relação, mesmo em sua diferença. Em outras palavras, há o perigo de manter a natureza como um outro diferente de mim no qual mantenho uma distância de observador, ou também considerar o homem como um "fator" da natureza e não uma relação de co-constituição, na qual o meu eu só se constitui a partir e com ela.

Por esse motivo, acreditamos que uma relação ética afastada dos moldes ocidentais, em que o outro é sempre um outro porque é diferente de mim, a 
partir do momento em que delimitamos a diferença com algum intuito, quase sempre pelo viés do poder, pretendemos levantar a hipótese de que por meio da filosofia ética africana ubuntu em que a natureza não é um outro fora de mim, mas um outro-com, poderemos reestabelecer os nexos ontológicos naturezahomem.

\section{Notas curriculares:}

Marcelo Moraes é professor concursado de Filosofia da Educação da Universidade do Estado do Rio de Janeiro. Graduação, mestrado e doutorado em Filosofia. Coordenador do projeto de pesquisa Filosofia africana e indígena. Editor da revista Ensaios Filosóficos. Concentra seus estudos nas áreas de: filosofia descolonial; Escrituras; Desconstruções; Filosofia africana e indígena; Filosofia antes dos gregos.

Mariane Bitetti é professora concursada do Departamento de Geografia da Universidade do Estado do Rio de Janeiro. Graduação, mestrado e doutorado em Geografia. Professora da PósGraduação do PPGG - FFP/UERJ. Coordenadora do Núcleo de Pesquisa Fundamentos da Geografia, Epistemologia e Ontologia. Concentra seus estudos nas áreas de: Epistemologia da Geografia, Geografias descoloniais, relação sociedade-natureza, geografia e alteridade. 


\section{Alexandre Nascimento, Juliana Magno, Anderson de Oliveira, Karine Oliveira, Farley Lobo \& Henrique Nascimento \\ UNIVERSIDADE DO ESTADO DE MINAS GERAIS / UNIVERSIDADE DO \\ ESTADO DE MINAS GERAIS / UNIVERSIDADE DO ESTADO DE MINAS GERAIS \\ / UNIVERSIDADE DO ESTADO DE MINAS GERAIS / PREFEITURA MUNICIPAL \\ DE BELO HORIZONTE}

\section{Observatório de Políticas Públicas pela Sustentabilidade (OPPS): Aproximando ciência, gestores políticos e cidadãos pela sustentabilidade no Brasil}

Palavras-Chave: sustentabilidade, políticas públicas, inovação, cidadania colaborativa

A necessidade de fixarmos a sustentabilidade como um valor sociocultural dominante é um dos maiores desafios do Antropoceno. Contraditoriamente, nunca foram tão expressivos o volume de produção científica e a enorme incerteza quanto ao futuro. A crise sistêmica, a insegurança e a instabilidade advêm do emergente colapso dos ecossistemas e da erosão da biodiversidade, em todas as escalas.

O Brasil, campeão mundial em biodiversidade, ainda apresenta um abismo entre ciência e atuação política, especialmente nos níveis mais locais, dos territórios e municípios. Tomadores de decisão e agentes políticos subutilizam a ciência e inovação tecnológica como ferramentas para governança mais eficaz e comprometida com os desafios complexos e interdependentes da atualidade. A implementação de políticas públicas pela sustentabilidade desafia a sociedade brasileira. Enfrentamos uma crise política e econômica que tem refletido em cortes recorrentes nos investimentos em ciência e tecnologia, prendendo-nos ao ciclo vicioso do empobrecimento e da desigualdade, colocando nosso país na posição de colônia moderna, que oferece matéria prima e recursos naturais ao mundo sem contabilizar impactos socioambientais diversos.

Ademais, após as eleições presidenciais de 2018, as políticas, normas e leis ambientais brasileiras têm enfrentado um crescente cenário de flexibilização, fragilização e vulnerabilidade. Esse desafio ressignifica o OPPS para além do que pensamos originalmente, colocando-o na linha de frente das 
iniciativas nacionais comprometidas com a ciência, o diálogo, a transparência e a cooperação para que a sustentabilidade seja norteadora da democracia.

O Observatório de Políticas Públicas pela Sustentabilidade (OPPS) nasce da crescente necessidade de integrar gestores políticos, pesquisadores e cidadãos pela solução de desafios socioambientais, aproximando a ciência da sociedade e suas demandas. Acreditamos que temos potencial disruptivo e inovador e que seremos capazes de fomentar comunicação estratégica e colaborativa, por territórios mais saudáveis e sustentáveis, valendo-nos da ciência e da inovação digital e tecnológica nesse processo.

Planejado como um projeto permanente, o OPPS iniciou suas atividades em março de 2018. Durante este primeiro ano de trabalho temos traçado o perfil e as principais demandas, desafios e experiências dos gestores políticos ambientais municipais. Iniciamos também um levantamento das principais inovações e startups capazes de contribuir para a sustentabilidade. Etapas seguintes envolvem o desenvolvimento, divulgação e gestão de uma ferramenta digital e o fomento a inteligência coletiva, disruptiva e colaborativa para lidar com os complexos desafios ambientais contemporâneos.

\section{Notas curriculares:}

Alexandre Nascimento é biólogo (Universidade Federal de Viçosa, 2002), Mestre em Ecologia Aplicada (Universidade de São Paulo, 2008), Doutor em Ecologia, Conservação e Manejo da Vida Silvestre (Universidade Federal de Minas Gerais, 2014). Profissional sênior em coordenação de projetos e pesquisas nas áreas de Ecologia Aplicada, Conservação da Biodiversidade e Políticas Públicas Ambientais. Experiência nas áreas de Biologia da Conservação, Ecologia Aplicada e Programas Integrados de Conservação da Biodiversidade e Desenvolvimento Sustentável, além de prática didática e em consultorias na área ambiental. Professor e pesquisador da Universidade do Estado de Minas Gerais (UEMG). Docente e orientador permanente do Programa de Mestrado Acadêmico em Ciências Ambientais da UEMG. Coordenador do Observatório de Políticas Públicas pela Sustentabilidade (OPPS).Juliana Magno é graduanda em Ciências Biológicas pela Universidade do Estado de Minas Gerais (UEMG). Ênfase em uma formação multidisciplinar a fim de atuar na Biologia da Conservação e fomentar a implementação de políticas públicas sustentáveis; membro da equipe do Observatório de Publicas pela Sustentabilidade (OPPS)

Anderson de Oliveira é graduando em Licenciatura em Ciências Biológicas na Universidade Federal de Minas Gerais (UFMG). Técnico em marketing do Centro Estadual de Educação Tecnológica Paula Souza.

Karine Oliveira é graduanda no curso de Ciências Biológicas pela Universidade do Estado de Minas Gerais (UEMG). Editora chefe na editora Venas Abiertas, produtora cultural (saraus periféricos) e estudante de iniciação cientifica no - PROGRAMA INSTITUGIONAL DE APOIO À PESQUISA (PAPq). Tem experiência na área de Biologia Geral, com ênfase em Educação. 
Farley Lobo é estagiário na secretaria municipal de meio ambiente de Peçanha e de João Monlevade;Coordenador de Gestão de Pessoas do Crea Minas Jr- Núcleo João Monlevade; Membro da Comissão Estadual de Gestão de Pessoas do Crea Minas Jr; campeão distrital de oratória e diretor da Avenida Comunidades pelo Clube de Rotaract de João Monlevade, distrito 4520; Assessor de Qualidade na Sênior Consultoria Ambiental Júnior.

Henrique Nascimento possui graduação em Ciências da Computação pela Universidade Federal de Minas Gerais(2003). Atualmente é Especialista em Desenvolvimento de Software do Fundação Para Inovações Tecnológicas. Tem experiência na área de Ciência da Computação, com ênfase em Teoria da Computação 


\section{Flávio de Oliveira}

UNIVERSIDADE FEDERAL DO PARÁ

\section{O Antropoceno e a revolução dos biomateriais. Diálogos entre Filosofia e Ciência dos Materiais na Amazônia do século x:xI}

Palavras-Chave: antropoceno, filosofia, ciência dos materiais, Amazônia

Este trabalho é o resultado parcial do projeto Olhares científicos através do açaí: segurança alimentar, revolução dos materiais e redução das desigualdades na comunidade amazônica desenvolvido no complexo de ilhas São Mateus em Barcarena-Pará/Brasil e que estabelece um diálogo crítico entre filosofia e ciência dos materiais. Propomos mostrar que a época do antropoceno é caracterizada pela promessa de uma sociedade da saúde, da beleza e do bem estar às custas da produtividade da natureza. Por conseguinte, a floresta amazônica transforma-se novamente no século XXI no Eldorado da ciência dos materiais e o espírito científico vai se familiarizando com o vocabulário exótico e nativo dos povos ribeirinhos, tais como: açaí, buriti, andiroba, etc. Esses frutos e vegetais representam, emblematicamente, o desejo de experimentar uma vida curativa, regenerativa, relaxante, enfim, uma vida pura, tendo em vista que um dos principais fundamentos da ciência dos materiais é extrair todas as qualidades e assimilar o potencial dos materiais. Com efeito, o antropoceno não deixa de fazer uma revolução no próprio corpo. Experiências com o xenoenxerto (uso do biomaterial de outra espécie) e com biomaterial quimicamente modificado (de origem vegetal ou animal) mostram que o antropoceno é uma criatura síntese que percebe o mundo como uma realidade bioabsorvível. Mas, se usarmos a noção benjaminiana (exposto no livro das Passagens) de que a ciência natural mecanicista criou uma cosmologia burguesa como um lugar de catástrofes permanentes, podemos constatar que uma nova cosmologia foi criada pelo antropoceno através da imagem do explorador e do conquistador de biomateriais, tais como: metais, cerâmicas e polímeros. Nesse sentido, indagamos: o antropoceno não está inaugurando um biocolonialismo? Propomos discutir essa questão pelo prisma do ecocriticismo que sustenta que o antropoceno é a fisionomia da expansão do capitalismo global e que vem transformando todos os entes naturais em formas de capital humano e, por fim, propomos uma reflexão do conceito do antropoceno confrontando-o com a noção da época do cosmocapitalismo (tal como exposto por Dardot e Laval) que diz respeito a submissão da vida à lógica de acumulação desigual do capital e que gera crescentes vulnerabilidades sociais, especialmente do risco da floresta 
não ser mais um espaço de democracia e patrimônio cultural para as comunidades amazônicas.

\section{Nota curricular:}

Doutor em Educação pela Universidade Federal do Pará/Brasil, com estágio doutoral na Faculdade de Ciência e Tecnologia da Universidade Nova de Lisboa. Mestre em Filosofia pela Universidade Estadual de Campinas-SP. Autor do livro Arte, Teologia e Morte: Filosofia e Literatura em Franz Kafka e Walter Benjamin. Curitiba: Appris, Brasil (2013). Coordenador do projeto Olhares Científicos através do açaí: segurança alimentar, revolução dos materiais e redução das desigualdades na comunidade amazônica (GNPq/Brasil). 


\section{Maria Adelaide Pacheco}

UNIVERSIDADE DE ÉVORA

\section{A saída do Antropoceno e a proposta de desautomatização de Bernard Stiegler}

Palavras-Chave: antropoceno, negantropoceno, desautomatização, decisão

Em La societé automatique 1. L'avenir do Travail, (Paris, Fayard, 20015), Bernard Stiegler analisa a crise da crise financeira de 2008 e as previsões do impacto da robótica na destruição do emprego, divulgadas pela primeira vez 2014, interpretando-as à luz do conceito de "Antropoceno".

Nesse ensaio, Stiegler mostra que o capitalismo financeiro tem-se apoderado dos desenvolvimentos tecnológico, moldando-o e selecionando os objetos técnicos capazes potenciar a sua dinâmica paradoxal de um futuro enriquecimento ilimitado a partir de uma insolvência atual.

Esta dinâmica paradoxal, marcada pelo entrosamento entre capitalismo financeiro e tecnociência, conduziu à criação de sofisticadas tecnologias capazes de transferir as tomadas de decisão para os sistemas técnicos, programados para gerir bases de dados em tempo real, culminando na robotização da indústria e da mobilidade e caminhando para numa gestão automatizada do oikos, em geral.

Em La Technique et le Temps (Paris, Editions Galilée, 1994) Stiegler já mostrara que a crescente autonomia e aceleração do desenvolvimento tecnológico interage com a temporalidade lenta própria do desenvolvimento dos sistemas sociais e culturais e com o tempo ainda mais lento do desenvolvimento dos sistemas biológico e ecológico. Contudo, o choque tecnológico associado à inteligência artificial e à robótica estaria a intensificar os efeitos desarticuladores de choques tecnológicos anteriores, potenciando um efeito catastrófico sobre o conjunto dos sistemas.

O Antropoceno, cujo início coincide com nascimento do capitalismo e a revolução industrial, por efeito do capitalismo neoliberal e da "revolução conservadora", teria entrado numa nova etapa: a época hiperindustrial, caracterizada pela proliferação dos mecanismos automáticos de controlo e pela liquidação do discernimento e da capacidade social e política de decisão.

Na perspetiva global do Antropoceno, e do ponto de vista "organológico" preconizado por Stiegler, trata-se do dum efeito desarticulador dos sistemas técnico, sobre os sistemas antropológicos de contenção pulsional e processos de individuação e de transindividuação. A "descapacitação" e "proletarização" das sociedades seriam o empobrecimento a nível social e cultural, 
correspondente à perda da biodiversidade, indicando um aumento da entropia do conjunto dos sistemas.

A possibilidade de saída do Antropoceno estaria, assim, ligada a uma alteração global no modo de funcionamento dos sistemas técnicos e não técnicos, e à possibilidade de estes se rearticularem e reinventarem, de modo produzir uma entropia negativa, ou "neguentropia".

A proposta de Stiegler, que visamos discutir, é a de tomar em conta os contributos de Marx e Nietzsche, para equacionar a possibilidade das tecnologias serem usadas para reparar as feridas abertas no tecido social, psicológico e ambiental, entrando numa nova era (o"Negantropoceno") de entropia negativa, onde possa ter lugar a desautomatização do trabalho .

\section{Nota curricular:}

Mestre em Filosofia pela Universidade de Lisboa (2003). Doutoranda na Universidade de Évora. Professora efectiva do Ensino secundário. Investigadora do Centro de Filosofia da Universidade de Lisboa (Pólo de Évora). Principais publicações: (2015): Linguagem, tradução e tradição. A recepção de Heidegger em português, Lisboa, Nota de Rodapé Edições, Paris, 382 pp. [ISBN 978989-20-5692-0, 382]; (2014): Ciência, Técnica e Práxis, In Borges-Duarte, I. \& Pardelha, I. (Org), Fenomenologia e Ciência. Atas do IV Congresso Internacional da Affen-III Congresso Luso-Brasileiro de Fenomenologia, pp 126-137, on line em http://www.affen.pt/iv-congresso-internacional-daaffen.-iii-congresso-luso-brasileiro-de-fenomenologia.html 


\section{Cláudia Toriz Ramos}

UNIVERSIDADE FERNANDO PESSOA

\section{Desenvolvimento sustentável e democratização, no Antropoceno: o caso da Guiné-Bissau}

Palavras-Chave: antropoceno, desenvolvimento sustentável, recursos naturais, Guiné-Bissau.

O "Antropoceno", conceito operatório para a análise da relação humanidade-natureza, ao presente, estabelece por isso uma relação conceptual com o conceito de 'sustentabilidade' que os debates, intelectuais e políticos, do mesmo presente vão consagrando.

No âmbito desta última, inserem-se relações intergeracionais de preservação da natureza, equilíbrios demográficos, problemas de segurança alimentar e sobrevivência imediata, autossuficiência e resiliência das comunidades humanas.

Nesta perspetiva, o continente africano, palco de muitas independências recentes e dos concomitantes processos de construção do Estado e da Nação, de tentativas de desenvolvimento e democratização, afigura-se um laboratório para a observação da interação destes vários processos, mantendo como questão primeira a interrogação sobre a matriz das relações humanidadenatureza aí estabelecidas.

A presente comunicação, partindo desse quadro teórico, abordará o caso da Guiné-Bissau, Estado independente desde 1974, cuja resiliência humana ainda não superou as barreiras do baixo desenvolvimento e da recorrente anarquia política. Serão por isso analisadas as condicionantes territoriais, climáticas, demográficas, histórico-culturais e políticas do processo de gestação desta 'comunidade política'. Serão também abordadas as múltiplas dimensões (nacional, regional, global) que enquadram e por isso condicionam esse processo.

\section{Nota curricular:}

Gláudia Toriz Ramos é PhD em Political Studies (2005) pela Universidade de Aberdeen, Reino Unido. É também detentora de MPhil (1992) e licenciatura em História (1986) pela Universidade do Porto, Portugal. É Professora Auxiliar na Universidade Fernando Pessoa, Porto, Portugal, onde leciona Política da União Europeia, Ciência Política, Globalização e seminários sobre Democracia e Cidadania. Os seus interesses de investigação cobrem a política da União 
Europeia, especialmente a partir da perspectiva das teorias da integração europeia e do desenvolvimento das instituições políticas - relações da sociedade, no contexto das democracias. Ela tem feito pesquisas sobre participação política, identidades políticas e legitimidade democrática. Ela tem interesse em estruturas de governança e democratização dentro dos vários quadros de governança multinível. 


\section{Bruno Rego}

UNIVERSIDADE DE LISBOA

\section{Paris no século Xx, Lisboa no século xxI ou a monotonização do mundo: a ideia de cidade no Antropoceno}

Palavras-Chave: cidade, tecnologia, antropoceno, unidimensionalização

Esta comunicação pretende reflectir sobre a relação entre cidade, tecnologia e economia no Antropoceno. Parte da visita a uma Paris distópica de um romance desconhecido de Jules Verne, Paris no Século $x x$, um esboço sombrio, porém actual, do humano numa sociedade hipertecnológica, para sustentar que na era do Antropoceno, sob diversas manifestações, a digitalização tecnológica da realidade e a uniformidade da racionalidade económica estão a desmaterializar e a unidimensionalizar a vivência cultural e histórica da cidade.

Em seguida, convoca-se Lisboa do século XXI como exemplo privilegiado da "monotonização do mundo" do habitar o espaço urbano, imposta por um determinado paradigma económico e tecnológico de pensar a ideia de cidade.

Conclui-se afirmando que cabe às humanidades, e não apenas à racionalidade económica e tecnológica, um papel mais activo no repensar a construção de lugares de habitabilidade da cidade, sob pena de esta se assemelhar à desencantadora Paris de Verne.

\footnotetext{
Nota curricular:

Bruno Rego (1979) é doutorado em Filosofia da Natureza e do Ambiente pela Faculdade de Letras da Universidade de Lisboa (2015). É autor das obras O Caos Global da Modernidade: O Século 21 segundo Ulrich Beck (Esfera do Caos, 2016) e Do Contrato Ambio-Social a uma Antropologia da Esperança: Cidadania e Sustentabilidade na Era da Crise Ambiental (Novas Edições Académicas, 2016).
} 


\section{Rosa Ricoy \& Hermes de Andrade Júnior \\ UNIVERSIDADE DE VIGO / UNIVERSIDADE CATÓLICA PORTUGUESA}

\section{(In) Segurança alimentar e nutricional no Antropoceno: Um estudo comparado entre Brasil e Espanha}

Palavras-Chave: segurança alimentar, insegurança alimentar, políticas públicas de segurança alimentar, Fome Zero.

Podemos estar vivendo no limiar de uma nova era. No argumento de que a ação humana tem alterado drasticamente o funcionamento e os fluxos naturais do planeta ao promover intensas mudanças globais, alguns especialistas afirmam que entramos em uma nova época geológica denominada de Antropoceno.

As constatações desse argumento são visíveis em todos os lugares por onde a espécie humana passa ou se estabelece. Algumas evidências dessa chamada "Era Antropocênica" podem ser observadas com a poluição de rios e oceanos por microplásticos e diferentes substâncias químicas; alteração nos níveis de nitrogênio pelo uso extensivo de fertilizantes na agricultura que também intensificam a toxidade biológica em geral; o aumento da dispersão de substâncias radioativas no planeta, após muitos testes com bombas nucleares, e, principalmente, as mudanças climáticas, discutidas nas altas esferas da política mundial.

Mais especificamente, a entrada no antropoceno tem permitido estudos dos reflexos ambientais sobre a questão dos alimentos como capacidade nutricional, agentes contaminantes, qualidade de vida, práticas de vida sustentável, ingestão de comprimidos como suplementação de vitaminas e outros nutrientes e também na busca pela ética e transparência na origem, processamento e armazenamento de alimentos.

Brasil e Espanha afirmam que tem políticas públicas sustentáveis reguladas tanto para a biotecnologia como para a agroecologia. No Brasil, o paradigma do Fome Zero revelou-se ineficaz em alguns desses fatores apontados e a Espanha continua a permitir o plantio e consumo de alimentos transgênicos à sua população, em que pese comportamentos de segurança alimentar como práticas de agricultura sustentável e orgânica em parte de seu território da população estarem trazendo bons resultados.

Nesse estudo, propomos uma visão comparada entre Brasil e Espanha, analisando aspectos ambientais que lhes são mais típicos, observados tanto na legislação como na aplicabilidade no terreno, buscando ressaltar os elementos de (in) segurança alimentar e nutricional. 


\section{Notas curriculares:}

Rosa Ricoy licenciou-se em Direito e em Ciência Política. Doutora em História. Professora Doutorada contratada do Departamento de Giência Política e Administração da Universidade de Vigo. Vicedecana da Faculdade de Ciências Sociais e Comunicação e Coordenadora do Curso de Administração e Gestão Pública. Professora Tutora com Venia Docendi em Direito e Ciência Política na UNED. Realiza orientações nível doutorado, mestrado e licenciaturas. Tem livro, capítulos e artigos publicados em revistas variadas.

Hermes de Andrade Júnior é bacharel em relações internacionais e também em ciências militares no Brasil. Possui um mestrado em sociologia e um doutorado em saúde pública, com ênfase na sociedade e no meio ambiente. É professor e pesquisador há mais de 15 anos, docente em faculdades/universidades brasileiras em várias disciplinas e consultor ad hoc da GAPES/Brasil na área de cooperação internacional. Tem livro, capítulos e artigos publicados em revistas variadas. Desde 2017 faz um pós-doutorado na Universidade Católica, sendo pesquisador sênior do Centro de Estudos Filosóficos e Humanísticos da Universidade em Braga (CEFH/UCP). Desenvolve em Portugal, em parceria, estudos de resiliencia (identidade nacional e resiliencia nacional) e competência ambiental e no Brasil, estudos de locus de controle e de percepção da conservação ambiental em universitários. 


\section{Richard Stahel}

UNIVERZITA KONSTANT'NA FILOZOFA V NITRE

\section{Sustainable retreat concept as an answer to anthropocene challenges}

Keywords:

Critical examination of possible socio-political anthropocene consequences leads to an end that the sustainable development concept is not an adequate answer for current threads and risks. An effort to implement the sustainable development concept can even deepen climate changes and other forms of nature devastation, as it turns out on ongoing greenhouse gas concentrations growth in the atmosphere, despite obligations that result to all states of the world from Paris agreement.

The climate change rate and range of plant and animal species extinction confirms J. Lovelock's thesis that humanity does not have enough time and, most likely, enough sources to implement the sustainable development concept and, as B. Latour points out, we do not have planet big enough.

Therefore, it is necessary to think about a retreat - to areas that are likely to stay habitable even after the sea level rise and desertification; it is necessary to think about how to move millions of people from areas flooded by sea or absorbed by desert; to think about a change of the way of life, of production of food and energy so that not only humankind as animal species would survive, but also our civilization and its technological and organizational knowledge. Even basic theses of this concept indicate a need to revalue majority political concepts, mainly concepts of sovereignty, citizenship, also the freedom of movement and residence, freedom of business and consume, which are fundamentals of neoliberal economic-political system.

Retreat expects elaborated and organized migration to beforehand chosen and arranged areas. Opposite to retreat is mass escape chaos that reduces human relations to fight for survival. As J. Lovelock proposed in his sustainable retreat concept, relocating people from areas affected by climate changes to climate oases would mean that rich northern countries give up their current, in fact, isolationistic politics that refuses climate migrants. Therefore, the sustainable retreat concept requires much greater competence and mainly willingness to cooperate not only on national, but also on international and global level more than humanity is able to do it currently. 


\section{Curricular note:}

Richard Stahel (1974) studied philosophy at the Comenius University in Bratislava (Slovakia). In years 1998-2004 he was reporter and editor in several all-state newspapers and journals. He defended his dissertation thesis in philosophy at the Commenius Universityin 2006. Since 2006 he works at the Department of Philosophy of Faculty of Arts at the Constantine the Philosopher University in Nitra (Slovakia), where he in 2017 habilitated in philosophy. In years 2010-2019 he was head of the Department of Philosophy of Faculty of Arts of Constantine the Philosopher University in Nitra (Slovakia). He is also co-founder of international scientific journal Philosophica Critica, whose he was editor in chief in years2015-2019. Since 2019 he is a director of Institute of Philosophy of Slovak Academy of Science in Bratislava. He has done research in political philosophy, philosophy of law, philosophy of state and environmental philosophy. His research is focused on the reciprocal conditionality of social, economic, political and environmental crises tendencies of the global industrial civilization and philosophical, social and political consequences of Anthropocene. He wrotetens of scientific papers and studies. Recently he is focusing on ecological civilization conception. He is author of book Pojem krizy $v$ environmentálnom myslení (The Concept of Crisis in Environmental Thinking, 2019), co-author of scientific monographies Environmentálna devastácia a sociálna deštrukcia. K otázke kritickej politickej ekológie (Environmental Devastation and Social Destruction. To the Question of Critical Political Ecology, 2016) and Človek, sloboda a vlastníctvo vo filozofii raného novoveku (Man, Freedom and Ownership in the Early Modern Philosophy, 2015). As an author and co-editor participated on publishing of international academic research volumes Človek, sloboda, vlastnictvo (Man, Freedom, Ownership, 2015), Filozofia a umenie żit'(Philosophy and the Art of Living, 2014), Idenitita-Diferencia (Identity-Difference, 2010) and Historické a súčasné podoby myslenia a komunikácie, (Historical and Contemporary Forms of Thinking and Communication, 2008). 


\section{Bernhard Sylla}

UNIVERSIDADE DO MINHO

\section{O Antropoceno - um naufrágio com espectador?}

Palavras-Chave: Blumenberg, metaforologia, antropoceno

O filósofo alemão Hans Blumenberg publicou, em 1979, uma análise detalhada sobre a metáfora "existencial" ("Daseinsmetapher") do naufrágio com espectador. Esta análise enquadra-se, na vasta obra de Blumenberg, por um lado, num conjunto de estudos que incidem sobre metáforas paradigmáticas que marcaram fortemente o rumo dos pensamentos humanos. Por outro lado, encontram o seu fundamento teórico nas reflexões metaforológicas do autor.

Três pressupostos blumenberguianos parecem-me, neste âmbito, importantes: (i) as metáforas fortes permitem que haja, ao longo da história do pensamento humano, variações surpreendentes e, frequentemente, imprevisíveis, sobre a sua primeira versão; (ii) estudar sob uma perspetiva histórica e simultaneamente topológica o desenvolvimento destas variações pode-nos esclarecer não apenas sobre o potencial já realizado, mas também sobre o potencial ainda não realizado destas metáforas; (iii) as metáforas exprimem uma forma peculiar de 'trabalhar' uma determinada problemática que não é entendível, racionalmente, em toda a sua extensão e profundidade.

A análise blumenberguiana da metáfora do naufrágio com espectador vai da Antiguidade até a meados do século XX. O que se pretende apresentar nesta comunicação é, para além de uma breve síntese do estudo de Blumenberg, uma reflexão acerca de novas variações sobre esta metáfora que surgiram no século XXI no âmbito do debate sobre o Antropoceno, portanto num tempo que Blumenberg, falecido em 1996, já não vivenciava. Esta reflexão terminará com considerações sobre o potencial ainda não realizado desta metáfora na era do Antropoceno.

\section{Nota curricular:}

Bernhard Sylla é Professor auxiliar do Departamento de Filosofia da Universidade do Minho e investigador do Centro de Ética, Política e Sociedade (CEPS) da mesma universidade. Desenvolve os seus trabalhos de investigação sobretudo nas seguintes áreas: Filosofia da Linguagem (tradições analítica e continental), Fenomenologia (especialmente Heidegger), Filosofia da Tecnologia (autores como Anders, Sloterdijk, Blumenberg). Publicou dois livros sobre a tradição continental da Filosofia da Linguagem e, em 2017, uma antologia de textos 
clássicos da Filosofia da Linguagem. É editor / co-editor de dois livros sobre fenomenologia e um sobre a filosofia da técnica de Dessauer. É autor de numerosos artigos científicos. 


\section{Rocío Carolo Tosar}

UNIVERSIDADE DE SANTIAGO DE COMPOSTELA

\section{El ser humano saudoso: la importancia del sentimiento en la reflexión filosófica}

Palabras-Clave: sentimiento, saudade, ser, intimidad

El ser humano ha sido objeto de reflexión dentro de la reflexión filosófica: ontología, epistemología, lenguaje, ... sin embargo ahora ha adquirido una mayor importancia reconociéndose su poder geomórfico dentro de la historia de la tierra, de ahí el nacimiento del concepto de Antropoceno.

Siempre fue reconocido el aspecto racional del ser humano, olvidándose en muchas ocasiones el lado sentimental. La fenomenología fue quién de dar el primer paso al mostrar al ser humano como ser sintiente, y fue más tarde cuando pensadores lusofonos revindicaron el sentimiento como parte fundamental del ser humano, y por lo tanto convirtiéndose en objecto de reflexión filosófica. Siguiendo a Paul Ricoeur, se empieza a establecer una implicación epistemológica entre conocimiento y sentimiento, afirmando "conocerse es sentirse".

Dentro de los sentimientos, hay un que goza de especial interés dentro de la lusofonia: a saudade. A saudade pasa por ser un sentimiento propio que lleva velado el ser del hombre, es decir, sentimiento y ontología vienen unidos a través de la Saudade.

En definitiva, este trabajo busca revindicar la importancia del sentimiento dentro de la visión actual del ser humano, en concreto del sentimiento de saudade por ser un sentimiento propio da región lusofona, y clave para el conocimiento do ser.

\footnotetext{
Nota curricular:

2008-2013. Licenciatura en Filosofía; por la Universidad de Santiago de Compostela; 2013-2014. Máster Universitario en Filosofía: Cuestións Actuais; por la Universidad de Santiago de Compostela; 2014-2015. Máster Universitario en Profesorado de Educación Secundaria Obligatoria e Bacharelato, Formación Profesional e Ensinos de Idiomas. Especialidade en Ciencias Sociais e Humanidades; por la Universidad de Santiago de Compostela; Desde 2016: Matriculado no programa de doctoramiento da USC, bajo la dirección del doctor D. Marcelino Agís Villaverde. Otros méritos: Participación en congresos nacionales e internacionales como el simposio internacional "Xerado Fdez. Albor e o seu tempo. Cen anos dun presidente", "XIV
} 
encuentros en el Camino de Santiago" o "XII Congreso Mundial de Metafísica"; Secretaria del Foro Galicia Milenio; Miembro de la junta directiva de la Sociedad Interuniversitaria de Filosofía. 


\section{Marcelino Agís Villaverde \\ UNIVERSIDADE DE SANTIAGO DE COMPOSTELA}

\section{La felicidad sostenible: nuevos modos de pensar lo humano en el antropoceno}

Palavras-Chave: humano, naturaleza, felicidad sostenible, valores

En el epílogo de mi libro Caminantes (de próxima aparición en versión portuguesa) introduje el concepto "felicidad sostenible" para expresar una nueva modalidad para entender el sentido de la existencia humana en una época que acertadamente se ha bautizado como "antropoceno". Aludía a la aspiración de ser feliz desde nuevas categorías en las que el hombe, más que sentirse el dueño y señor de la naturaleza, aprenda a convivir y a valorar las pequeñas cosas que le rodean y que hacen su vida sostenible, tanto desde el punto de vista físico como moral.

\footnotetext{
Nota curricular:

Licenciado en Filosofía e Ciencias da Educación pola Universidade de Santiago de Compostela en 1986. Estudos de posgraduado en París e Chicago con Paul Ricoeur. Doutor en Filosofía pola USG (1992). Profesor visitante da Universidade de Perugia (1995), Universidade Presbiteriana Mackenzie (2005 e 2007). Profesor invitado nas Universidades Technische Universität de Berlín, Coímbra, Porto, Instituto Superior de Psicoloxía Aplicada de Lisboa, Universidade do Minho (Braga), Tenri (Xapón), São Paulo, Roma III, Istituto Italiano per gli Studi Filosofici (Nápoles), Kansas University (USA) e Universidade Popular Autónoma do Estado de Puebla (México). É profesor de Filosofía na Facultade de Filosofía da USG desde 1996, profesor titor da UNED e profesor colaborador do Instituto Teolóxico Compostelán (Universidade Pontificia de Salamanca). Foi vicerreitor de Terceiro Ciclo e Extensión Docente (2002-2006).
} 
